\title{
MiR-21 protected against diabetic cardiomyopathy induced diastolic dysfunction by targeting gelsolin
}

\author{
Beibei Dai ${ }^{1,2}$, Huaping $\mathrm{Li}^{1,2}$, Jiahui Fan ${ }^{1,2}$, Yanru Zhao ${ }^{1,2}$, Zhongwei Yin ${ }^{1,2}$, Xiang Nie ${ }^{1,2}$, Dao Wen Wang ${ }^{1,2^{*}}$ \\ and Chen Chen ${ }^{1,2^{*}}$
}

\begin{abstract}
Background: Diabetes is a leading cause of mortality and morbidity across the world. Over $50 \%$ of deaths among diabetic patients are caused by cardiovascular diseases. Cardiac diastolic dysfunction is one of the key early signs of diabetic cardiomyopathy, which often occurs before systolic dysfunction. However, no drug is currently licensed for its treatment.

Methods: Type 9 adeno-associated virus combined with cardiac Troponin T promoter were employed to manipulate miR-21 expression in the leptin receptor-deficient (db/db) mice. Cardiac structure and functions were measured by echocardiography and hemodynamic examinations. Primary cardiomyocytes and cardiomyocyte cell lines were used to perform gain/loss-of-function assays in vitro.

Results: We observed a significant reduction of miR-21 in the diastolic dysfunctional heart of $\mathrm{db} / \mathrm{db}$ mice. Remarkably, delivery of miR-21 efficiently protected against the early impairment in cardiac diastolic dysfunction, represented by decreased ROS production, increased bioavailable $\mathrm{NO}$ and relieved diabetes-induced cardiomyocyte hypertrophy in $\mathrm{db} / \mathrm{db}$ mice. Through bioinformatic analysis and Ago2 co-immunoprecipitation, we identified that miR-21 directly targeted gelsolin, a member of the actin-binding proteins, which acted as a transcriptional cofactor in signal transduction. Moreover, down-regulation of gelsolin by siRNA also attenuated the early phase of diabetic cardiomyopathy.

Conclusion: Our findings reveal a new role of miR-21 in attenuating diabetic cardiomyopathy by targeting gelsolin, and provide a molecular basis for developing a miRNA-based therapy against diabetic cardiomyopathy.
\end{abstract}

Keywords: miRNA, Diabetic cardiomyopathy, Diastolic dysfunction, ROS, NO

\section{Introduction}

Diabetes mellitus is firmly established as a major threat to human health in the twenty-first century due to its alarming rise in incidence over the past two decades, which has attracted considerable attention $[1,2]$. Cardiovascular disease is the primary cause of severe morbidity and mortality among the diabetic population. Both experimental and clinical evidences suggest that diabetic subjects are predisposed to a distinct cardiomyopathy,

\footnotetext{
*Correspondence: dwwang@tjh.tjmu.edu.cn; chenchen@tjh.tjmu.edu.cn ${ }^{1}$ Division of Cardiology, Department of Internal Medicine, Tongji Hospital, Tongji Medical College, Huazhong University of Science and Technology, 1095\# Jiefang Ave., Wuhan 430030, China

Full list of author information is available at the end of the article
}

independent of concomitant macro- and microvascular disorders. Diabetic cardiomyopathy is characterized by early impairments in diastolic function, accompanied by the development of cardiac hypertrophy, myocardial fibrosis, and cardiomyocyte apoptosis [3]. However, the pathophysiology of diabetic cardiomyopathy is incompletely understood and currently no specific therapy is available.

Diastolic dysfunction is one of the early key signs of diabetic cardiomyopathy, which often occurs before systolic dysfunction [4-6]. The onset of diabetic cardiomyopathy is characterized by mild cardiac hypertrophy and diastolic dysfunction with preserved systolic function, then leading to heart failure with reduced ejection 
fraction [7]. A recent study found that compared with heart failure patients without diabetes, diastolic ventricular stiffness was much greater in failing hearts of diabetic patients in the absence of significant coronary artery disease [8]. In addition to impaired systolic function, diabetes and diastolic dysfunction also play important roles in heart failure progress $[9,10]$. However, the relationship between the commonly observed metabolic abnormalities and the specific cardiac phenotype is unclear [2]. It was reported that increased myocardial deposition of collagen was responsible for cardiac remodeling and diastolic stiffness in diabetic heart $[8,11]$. Myocardial triglyceride accumulation also resulted in diastolic abnormalities [2]. The balance between the generation of ROS and their removal via antioxidant degradation is critical for the maintenance of cardiovascular health. Increased ROS formation also played an integral role in cardiac dysfunction [12, 13]. Decreased NO level contributed to diastolic stiffness $[14,15]$, while restoration of eNOS-NO signaling ameliorated diabetic heart dysfunction $[3,16]$. However, the exact pathogenesis of idiopathic diabetic cardiac dysfunction has yet not been elucidated [3].

MicroRNAs (miRNAs) are a class of endogenous small non-coding RNAs, which emerge as powerful regulators in many essential biological processes [17]. But the roles of miRNAs in diabetes and its cardiovascular complications are not fully discovered [18-20]. It was reported that miR-195 increased ROS production via Sirt1 and Bcl-2, and inhibition of miR-195 may be a promising therapeutic strategy for lipotoxic cardiomyopathy [21]. miR-30d promoted cardiomyocyte pyroptosis in diabetic cardiomyopathy [22]. Kuwabara et al. revealed that highfat diet-induced cardiac hypertrophy was ameliorated in cardiomyocyte-specific miR-451 knockout mice [23]. Similarly, we found that miR-30c was crucial in diabetic cardiomyopathy by regulating autophagy [24]. Circulating miRNAs are considered as potential biomarkers of various diseases [25]. Decreased plasma level of miR21 was found in patients with diabetes in large population-based cohorts [26-28]. Recently, it was found that miRNAs mediated the benefits of exercise and bariatric surgery to the heart in diabetic/prediabetic patients, and the decreased circulating miR-21 were restored after bariatric surgery or physical activity [25, 29]. Moreover, upregulation of miR-21 or downregulation of its targets could lead to diabetic cardiac dysfunction [30-32]. Therefore, miR-21 might play important roles in diabetic cardiomyopathy, and it may be a new therapeutic target for metabolic diseases such as T2DM and obesity. However, the roles of miR-21 in cardiac diseases are controversial. Thomas et al. showed that miR-21 promoted cardiac fibroblast survival, which led to fibrosis, hypertrophy and cardiac dysfunction [33], whereas Cheng et al. found that miR-21 protected against the $\mathrm{H}_{2} \mathrm{O}_{2}$-induced damage in cardiac myocytes via PDCD4 and AP-1 pathway [34]. A study reported that high glucose increased the expression level of miR-21 in fibroblasts from heart, and miR-21 promoted collagen synthesis in vitro [35]. Recent studies found that miR-21 inhibition significantly decreased body weight, adipocyte size and serum triglycerides, on the other hand, miR-21 reversed high glucose and high insulin induced IR in 3T3-L1 adipocytes, possibly through modulating the PTEN-AKT pathway [31, 36]. It was supposed that the same miRNA from different cell sources may exert various effects on the same disease $[25,37,38]$. Previously, we revealed a positive function of miR-21 in mitochondrial translation, which was sufficient to reduce blood pressure and alleviate cardiac hypertrophy in spontaneous hypertension rat [39]. By now, not only the role of miR-21 in diabetic cardiomyopathy is unclear, but also the predominate functional cell type in diabetic cardiomyopathy remains unknown.

In the present study, we investigated the roles of miR21 in diastolic dysfunction of early diabetic cardiomyopathy in vitro and in vivo, and found that miR-21 protected against diastolic dysfunction and cardiac hypertrophy, by reducing ROS production via gelsolin in $\mathrm{db} / \mathrm{db}$ mice, which suggested a new therapeutic strategy against diabetic cardiomyopathy.

\section{Research design and methods}

\section{Cell culture and transfection}

H9c2 and HEK293 cells from ATCC (Manassas, VA) were maintained in H-DMEM supplemented with $10 \%$ FBS at $37{ }^{\circ} \mathrm{C}$ with a $95 \%$ air, $5 \% \mathrm{CO}_{2}$ atmosphere. Cells were incubated with normal $(5 \mathrm{mM})$ or high $(33 \mathrm{mM})$ glucose for $48 \mathrm{~h}$ and then collected. For high fatty acid (FA) stimulation, H9c2 cells were treated with palmitate $(250 \mu \mathrm{M})$ for $48 \mathrm{~h}$, as previously described [24].

HL-1 cell line, which is a cardiac muscle cell line derived from the AT-1 mouse atrial cardiomyocyte tumor lineage was also from ATCC (Manassas, VA). And cells were cultured in Claycomb Medium (Sigma, Shanghai, China) with 10\% FBS, $4 \mathrm{mM}$ L-gutamine (Sigma, Shanghai, China) and $100 \mu \mathrm{M}$ norepinephrine (Sigma, Shanghai, China) at $37{ }^{\circ} \mathrm{C}$ with a $95 \%$ air, $5 \% \mathrm{CO}_{2}$ atmosphere as previously described [40].

Human cardiomyocytes were purchased from Sciencell (San Diego, CA, Catalog Number: 6200). Cells were carefully cultured according to product instruction.

MiRNA mimics, miRNA inhibitor, siRNAs and relative controls were purchased from RiboBio (Guangzhou, China). Transfection with miR-21 mimics (100 nM), siRNAs $(100 \mathrm{nM})$, and relative controls $(100 \mathrm{nM})$ was performed with Lipofectamine 2000 (Invitrogen, Carlsbad, $\mathrm{CA})$, according to the manufacturer's recommendations. 


\section{Isolation of primary cardiomyocytes}

Cardiomyocytes (CMs) and non-cardiomyocytes (NCMs) were isolated from adult mice, as described previously [41]. Firstly, we perfused and digested the left ventricles of hearts, and then dissected them into small pieces for dissociation in transfer buffer. Secondly, we filtered the cell solution and the cells were settled by sedimentation for several minutes in Falcon tubes. After that, we transferred cell pellets and supernatants to other Falcon tubes for further separation. Cell pellets were resuspended in transfer buffer and settled by repeated precipitation for twice. After a second precipitation, the cell pellets were examined for typical rod-shaped cell morphology before RNA extraction to verify the expression of CM markers. The initial supernatant was first centrifuged at $50 \mathrm{~g}(3 \mathrm{~min})$ and then at $300 \mathrm{~g}(5 \mathrm{~min})$ before verification of the pelleted cell NCM identity by qRT-PCR assessment of fibroblast and CM markers (Additional file 1: Fig. S1) [42].

\section{FFA preparation}

FFA solutions were prepared as described previously [43]. Briefly, $100 \mathrm{mM}$ palmitate (Sigma, P9767, Shanghai, China) stocks were prepared in $0.1 \mathrm{M} \mathrm{NaOH}$ at $70^{\circ} \mathrm{C}$ and filtered. Twenty percent (weight/volume) palmitatefree BSA (Sigma, A2153, Shanghai, China) solution was prepared in serum-free DMEM. After the palmitate dissolved, the palmitate solutions were added to serumfree DMEM containing BSA. The $25 \mathrm{mM}$ palmitate/20\% BSA solution was prepared by complexing appropriate amounts of palmitate to $20 \% \mathrm{BSA}$ in a $40{ }^{\circ} \mathrm{C}$ water bath.

\section{Western blotting}

Protein concentrations were determined by the BCA method. For Western blotting, total cell lysate was resolved by SDS-PAGE, transferred to PVDF membrane, and blocked with 5\% non-fat dry milk in TBS-T. The membrane was incubated with primary antibody overnight at $4{ }^{\circ} \mathrm{C}$, followed by peroxidase-conjugated secondary antibody for $2 \mathrm{~h}$, and finally developed with the ECL system (Beyotime Institute of Biotechnology, Nanjing, China). Antibodies against phospho-eNOS (Ser1177) (Catalog No: 9570s), phospho-eNOS (Thr495) (Cata$\log$ No: 9574s), and eNOS (Catalog No: 32027s) were purchased from Cell Signaling Technology (Shanghai, China). Anti-GAPDH was from Tianjin Sungene Biotech Co., Ltd. (Tianjin, China) (Catalog No: KM9002T). Anti-Akt1/2/3 (Ser473) (Catalog No: sc-8312) and antip-Akt1/2/3 (Ser473) (Catalog No: sc-7985-R) were from Santa Cruz Biotech (Santa Cruz, CA). Anti-gelsolin (Catalog No: ab134183) was from Abcam (Shanghai, China).
Western blotting results were quantified by densitometry and processed with the ImageJ software (National Institutes of Health software).

\section{RNA isolation and detection}

Total RNA was collected from frozen tissues or cells by TRIzol Reagent (Invitrogen, Carlsbad, CA) according to the manufacturer's protocol. Then, total RNA $(2 \mu \mathrm{g})$ was reverse transcribed using the first-strand cDNA synthesis kit (Thermo Scientific, Carlsbad, CA). Amplification and detection of specific products were performed on a 7900HT Fast Real-Time PCR system (Applied Biosystems, Foster City, CA). The Bulge-LoopTM miRNA qPCR Primer Sets (RiboBio, Guangzhou, China) were used to detect miRNA expression. The primers of gene PCR were synthesized by Tianyihuiyuan (Wuhan, China) were used to access mRNA expression levels. U6 was used as an internal control for miRNA template normalization, and GADPH was used for mRNA template normalization. The sequences of the primers used were listed in Additional file 1: Table S1. The qRT-PCR reactions were run in triplicate, and the signal was collected at the end of every cycle. The relative gene expression was calculated by comparing cycle times $(\mathrm{Ct})$ for each target PCR as previously described [44]. The qRT-PCR productions were collected for sequencing to validate the specific of gene primers.

\section{RNA immunoprecipitation}

Twenty-four hours after transfection with miR-21 mimics or miRNA random control, cells were lysed and then immunoprecipitated with anti-Ago2 antibody (Abnova Corporation, Taiwan, China) or IgG (Abclonal, Wuhan, China) using protein A/G magnetic beads (Thermo Scientific, Shanghai, China), as described [45]. After incubating the cells overnight at $4{ }^{\circ} \mathrm{C}, 40 \mu \mathrm{L}$ of protein $\mathrm{A} / \mathrm{G}$ magnetic beads were added, and the solution was incubated for $2 \mathrm{~h}$ at $4{ }^{\circ} \mathrm{C}$. The beads were washed five times with PBS and resuspended in $60 \mu \mathrm{L}$ Laemmli buffer. The remaining products were extracted with TRIzol, and the levels of mRNA were quantified by real-time PCR.

\section{Construction of rAAV}

To manipulate the expression of miR-21 in vivo, the rAAV (type 9) combined with cardiac troponin $\mathrm{T}$ (cTnT) promoter was employed. The rAAV system (type 9) was a kind gift from Dr. Xiao Xiao (University of North Carolina at Chapel Hill). For construction of the adenoviruses, oligonucleotides were designed as miR-21, (5-TGCACTGCAGTAGCT TATCAGACTGATGTT GATTCAAGAGATCAACATCAGTCTGATAAGCTA CCATGGCATG-3), miR-21-TUD, (5-GACGGCGCT AGGATCATCAACATCGAATAGTTCTACTGACTA 
CAACTACAAGTATTCTGGTCACAGAATACAACA TCGAATAGTTCTACTGACTACAACTACAAGATG ATCCTAGCGCCGTC-3) according to the mature sequence of hsa-miR-21 provided by miRBase (Accession: MIMAT0000076). Then, the oligonucleotides were synthesis and inserted into pAAV vector at PstI and NcoI sites. These vectors were named pAAV-tnt-miR-21 and pAAV-tnt-miR-21-TUD, respectively. The constructs were sequenced to confirm the DNA sequences. The designed gene plasmid, pXX9, and pHelper were packaged together by triple plasmids co-transfection in HEK293 cells, and then purified as described previously [46]. The resultant rAAVs were assigned as rAAV-GFP, rAAV-tnt-miR-21, rAAV-tnt-miR-21-TUD, and rAAVtnt-GFP, respectively. The specificity of cardiac delivery was determined by GFP detection (Additional file 1: Fig. S2).

\section{Animals}

All experiments were performed with the approval of the Animal Research Committee of Tongji Medical College, and in accordance with ARRIVE and NIH guidelines for animal welfare. For in vivo experiments, male $\mathrm{db} / \mathrm{db}$ mice on C57BL/Ks background and control C57BL/Ks mice (Model Animal Research Center of Nanjing University, Nanjing, China) were used. All the animals were maintained with 12-h light/12-h dark photoperiods with free access to water and food. We randomly divided $\mathrm{db} /$ $\mathrm{db}$ mice into four groups (control, rAAV-tnt-GFP, rAAVtnt-miR-21, and rAAV-tnt-miR-21-TUD, $\mathrm{n} \geq 8$ each group). They were injected with corresponding rAAVs via tail vein at the age of 8 weeks. All surgery was performed under sodium pentobarbital anesthesia to minimize suffering. Through intraperitoneal injections of a ketamine $(80 \mathrm{mg} / \mathrm{kg})$ and xylazine $(5 \mathrm{mg} / \mathrm{kg})$ mixture, anaesthetization of mice was performed. To assess the adequacy of anesthesia during hemodynamic examinations, parameters such as responsiveness, blood pressure, respiratory and heart rates were monitored. Then they were sacrificed by $\mathrm{CO}_{2}$ inhalation after the surgical procedures. The $\mathrm{rAAV}$-treated $\mathrm{db} / \mathrm{db}$ and control C57BL/Ks mice were sacrificed at 20 weeks and tissue samples were snap-frozen in liquid nitrogen or collected for paraffin embedding.

\section{Hemodynamic analyses}

Mouse hemodynamics were assessed as previously described [47]. After anaesthetization, left ventricular (LV) catheterization was performed on mice before sacrifice. The portion of the right carotid artery next to the trachea was isolated from the surrounding tissue and nerves. A 1.0 Fr Millar Mikrotip Catheter Transducer (Millar 1.4F, SPR 835, Millar Instruments, Houston, TX) connected to a pressure transducer (Millar Instruments, Houston, TX) was inserted through the right carotid artery into the LV cavity. Hemodynamic parameters were recorded and analyzed with PowerLab/8sp and LabChart 7.2.1 software. PVAN software (Millar Instruments, Houston, TX) was used to perform the cardiac pressure-volume analysis. The peak instantaneous rate of the LV pressure increase and decline (dp/dt max, $\mathrm{dp} /$ $\mathrm{dt} \mathrm{min}$ ) were measured. All data were averages of at least five measurements, each measurement concluded at least ten successive loops.

\section{Echocardiography}

After anesthetization, echocardiographic analysis was performed to determine cardiac function of 20-weekold mice using a high-resolution imaging system with a $30-\mathrm{MHz}$ high frequency scanhead (VisualSonics Vevo770, VisualSonics, Toronto, Canada), as described previously [24]. Briefly, a parasternal long-axis B-mode image was acquired with appropriate positioning of the scan head, so that the maximum LV length could be identified. Then a clockwise 90 rotation at the papillary muscle level depicted the parasternal short-axis view. An M-mode cursor was positioned perpendicular to the anterior and posterior walls of the left ventricle from this view and M-mode image loops were obtained for measurement of wall thickness and chamber dimensions. Each of these captured image loops included 11-20 cardiac cycles, and data were averages from at least three cycles per loop.

LVEF was calculated as follows: $L V E F=($ left ventricular end-diastolic volume [LVEDV]-left ventricular end-systolic volume [LVESV])/LVEDV $\times 100 \%$. FS was calculated as follows: FS \%=(left ventricular end diastolic dimension [LVDd]-left ventricular end systolic dimensions [LVDs] / /LVDd $\times 100 \%$.

\section{Histological analysis}

Formalin-fixed hearts were embedded in paraffin and sectioned into $4 \mathrm{~mm}$ slices. The morphology was detected by H\&E staining. Oil Red O staining was applied to $7 \mu \mathrm{m}$ frozen sections. Lipid deposition were visualized by microscope, and measured by Image-Pro Plus Version 6.0 (Media Cybernetics, Bethesda, MD). The oxidative fluorescent dye, dihydroethidium (DHE; Invitrogen, Carlsbad, CA) was applied to $7 \mu \mathrm{m}$ frozen sections from hearts at $40 \mu \mathrm{mol}$ for $30 \mathrm{~min}$. Fluorescence intensity was measured under a Nikon DXM1200 fluorescence microscope and images were analyzed with the Image-Pro software (Media Cybernetics, Bethesda, MD). Total ROS was quantified using 2,7-dichlorodihydrofluorescein diacetate (DCFH-DA, Invitrogen, Carlsbad, CA). TUNEL staining 
and Sirius Red Staining were also applied to detect apoptotic cells and myocardial fibrosis in hearts.

\section{Biochemistry examinations}

Biochemical parameters TC, TG, LDL, and HDL in plasma, TC and TG in heart or H9c2 cells were detected by GRO-PAP method (Nanjing Jiancheng Bioengineering Institute, Nanjing, China). After mice were fasted overnight, blood glucose level was measured by Glucose LiquiColor Test (Stanbio Laboratory, Boerne, TX) every 4 weeks.

\section{Measurements of NO production}

The concentration of NO was measured as nitrite (the final stable state of $\mathrm{NO}$ ) accumulation in the culture medium using a NO assay kit (Beyotime, Nanjing, China) according to the manufacture's instruction. Briefly, $50 \mu \mathrm{L}$ of supernatant was subjected to colorimetricreaction with Griess reagents. After reaction, the NO concentration was quantified by absorbance at $540 \mathrm{~nm}$ using a microplate reader (BIO-TEK Instruments, Shanghai, China).

\section{Dual luciferase assay}

First, we transfected 400 ng of pMIR-GSN $3^{\prime}$ UTR, pMIRGSN 3' UTR mutant, or the empty vector into HEK293 cells with 40 ng of pRL-TK plasmid (Promega, Madison, $\mathrm{WI})$, respectively. Then, miR-21 mimics or miR-con was co-transfected with those reporter plasmids at a final concentration of $100 \mathrm{nM}$. Forty-eight hours later, luciferase activity was detected by Dual-Luciferase Reporter Assay System (Promega, Beijing, China) according to the manufacturer's protocol. Renilla luciferase activity was used to normalize the transfection efficiency.

\section{Statistics}

All data are analyzed using Prism 5 (GraphPad Software, San Diego, CA) and presented as mean \pm SEM. The Student's $t$ test and ANOVA were performed to determine statistically significant differences among treated groups, as appropriate. In all cases, a value of $\mathrm{p}<0.05$ was considered to be statistically significant.

\section{Results}

\section{Overexpression of miR-21 protects against diastolic dysfunction in $\mathrm{db} / \mathrm{db}$ mice}

To explore the roles of miR-21 in the early phase of diabetic cardiomyopathy, real-time PCR was used to detect miR-21 expression in 20-week-old $\mathrm{db} / \mathrm{db}$ mice, a well-established animal model of diabetic cardiomyopathy [48]. Compared with wild type controls, significantly decreased miR-21 was observed in heart of $\mathrm{db} /$ db mice (Fig. 1a). Interestingly, miR-21 was specifically down-regulated in cardiomyocytes of $\mathrm{db} / \mathrm{db}$ mice (Fig. 1b). Similarly, high fat diet-induced diabetic mice also showed a significant decrease of miR-21 expression in cardiomyocytes as $\mathrm{db} / \mathrm{db}$ mice (Fig. 1c).

Next, we employed the $\mathrm{db} / \mathrm{db}$ mice model to investigate the roles of myocardial miR-21 in the early phase of diabetic cardiomyopathy by using rAAV combined with cTnT promoter delivery system. Compared with wild type controls, miR-21 was decreased in $\mathrm{db} / \mathrm{db}$ mice heart, and cardiac miR-21 level was increased in rAAV-tnt-miR-21 treated mice, while rAAV-tnt-miR-21TUD (tough decoy) treatment exerted opposite effects (Fig. 1d). As shown in Fig. 1e, f, 2a and Additional file 1: Fig. S3A-G, there was no significant change in systolic function among the control and treated mice, which was consistent with previous data [4-6]. However, miR21 overexpression rescued diastolic dysfunction in $\mathrm{db} /$ $\mathrm{db}$ mice (Fig. 2b, Additional file 1: Fig. S3H). Moreover, blood glucose, body weight, LDL, TG, and TC levels were increased in $\mathrm{db} / \mathrm{db}$ mice, but cardiac overexpression or inhibition of miR-21 had no effects on these metabolic characteristics (Additional file 1: Fig. S4).

Our data indicated that cardiac specific overexpression of miR-21 protected against diastolic dysfunction, which was the key early phase sign of diabetic cardiomyopathy in $\mathrm{db} / \mathrm{db}$ mice, independent of systemic metabolic improvements, such as blood glucose and lipid levels.

\section{MiR-21 protects against cardiac hypertrophy in diastolic dysfunction $\mathrm{db} / \mathrm{db}$ mice}

To further investigate the mechanisms underlying diastolic dysfunction, we found that cardiac hypertrophy was increased in $\mathrm{db} / \mathrm{db}$ mice compared with wild type controls (Fig. 3a). Consistently, overexpression of miR-21 significantly decreased while inhibition of miR-21 increased cardiac hypertrophy in $\mathrm{db} / \mathrm{db}$ mice (Fig. 3a). Moreover, the expression of hypertrophy markers, such as ANP, $\mathrm{BNP}$, and $\beta-/ \alpha-\mathrm{MHC}$ ratio showed a similar change in treated db/db mice (Fig. 3b-d). However, there was neither fibrosis nor apoptosis among all groups (Additional file 1: Fig. S5A, B). Although lipid deposition measured by Oil Red was increased in $\mathrm{db} / \mathrm{db}$ mice heart compared to controls, miR-21 had no effect on lipid deposition in $\mathrm{db} / \mathrm{db}$ mice heart (Additional file 1: Fig. S5C, D). These data suggested that miR-21 did not participate in diastolic dysfunction via regulating fibrosis, apoptosis or lipid accumulation in $\mathrm{db} / \mathrm{db}$ mice.

It was reported that ROS may contribute to the initial cardiac diastolic dysfunction, while increasing NO bioavailability maybe beneficial for recovering impaired diastolic function in diabetes [12-15, 49]. Interestingly, we found elevated cardiac ROS levels in $\mathrm{db} / \mathrm{db}$ mice in comparison with wild type controls, and overexpression 
a

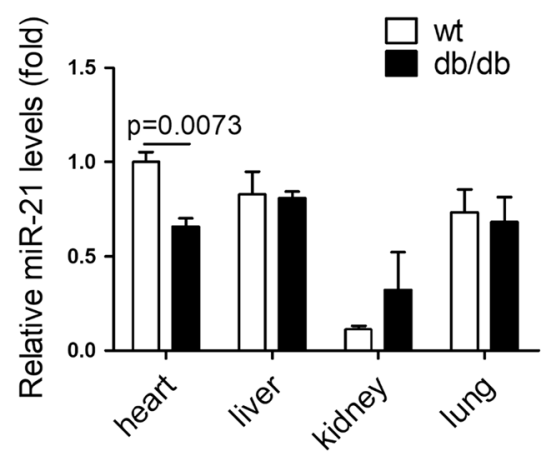

c

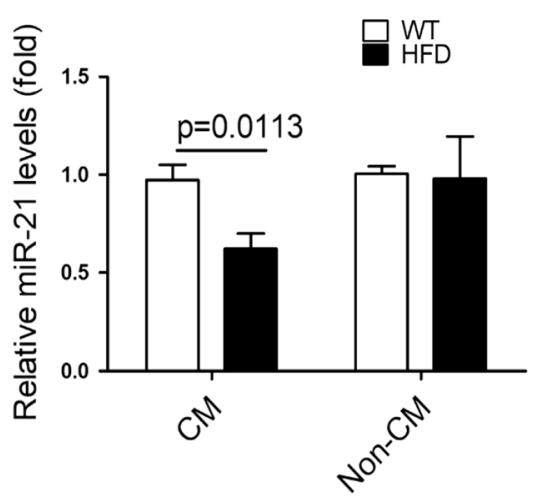

e
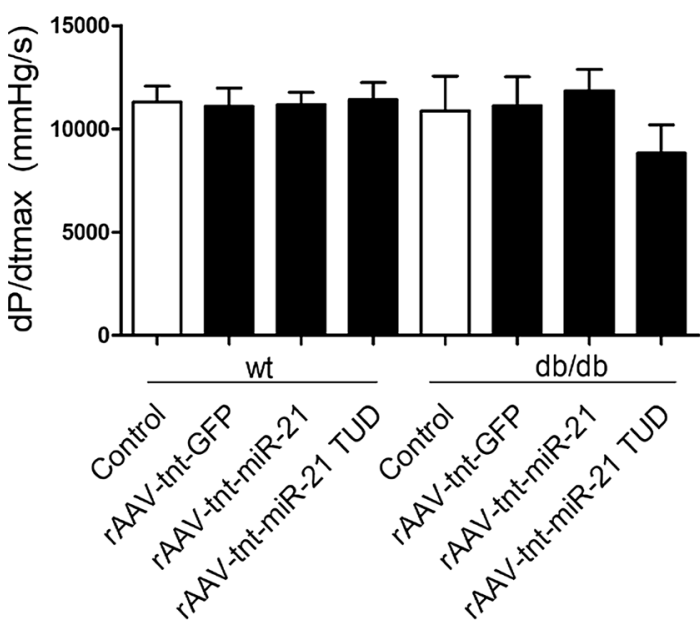

b 음

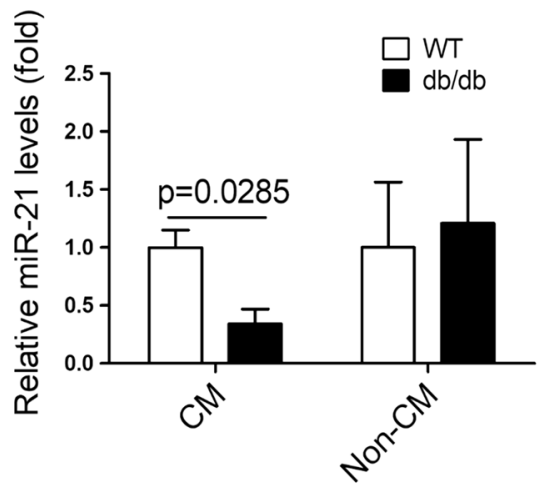

d

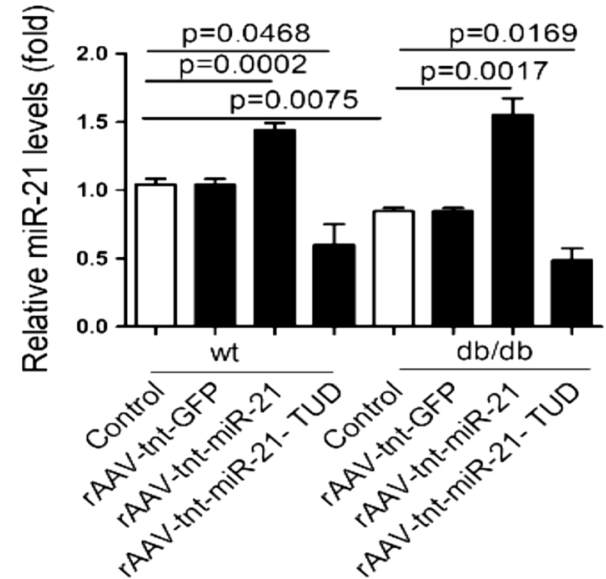

f
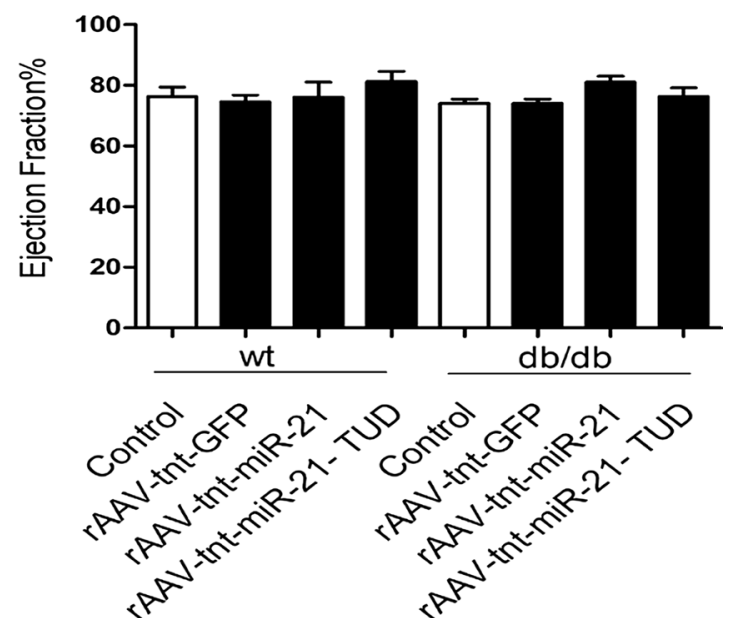

Fig. 1 Overexpression of miR-21 protects against diastolic dysfunction in $\mathrm{db} / \mathrm{db}$ mice. a Relative expression of miR-21 among different organs. b Relative expression of miR-21 in isolated CMs and NCMs from db/db mice. c Relative expression of miR-21 in isolated CMs and NCMs from high fat diet fed mice. $\mathbf{d}$ Relative expression of miR-21 in heart from treated mice. e Hemodynamic analysis of db/db mice and C57BL/Ks controls. dp/dt $t_{\text {max }}$ peak instantaneous rate of LV pressure increase. $\mathbf{f}$ Echocardiographic analysis of $\mathrm{db} / \mathrm{db}$ mice and controls. EF\% (ejection fraction) was quantitatively analyzed

of miR-21 decreased ROS levels in db/db mice (Fig. 3e). Meanwhile, we observed reduced NO level in the heart of $\mathrm{db} / \mathrm{db}$ mice, and miR-21 increased while miR-21-TUD decreased NO level in $\mathrm{db} / \mathrm{db}$ heart (Fig. 4a). It was reported that increased phosphorylation of Akt at Ser473 and eNOS at Ser1177 may improve NO release and 

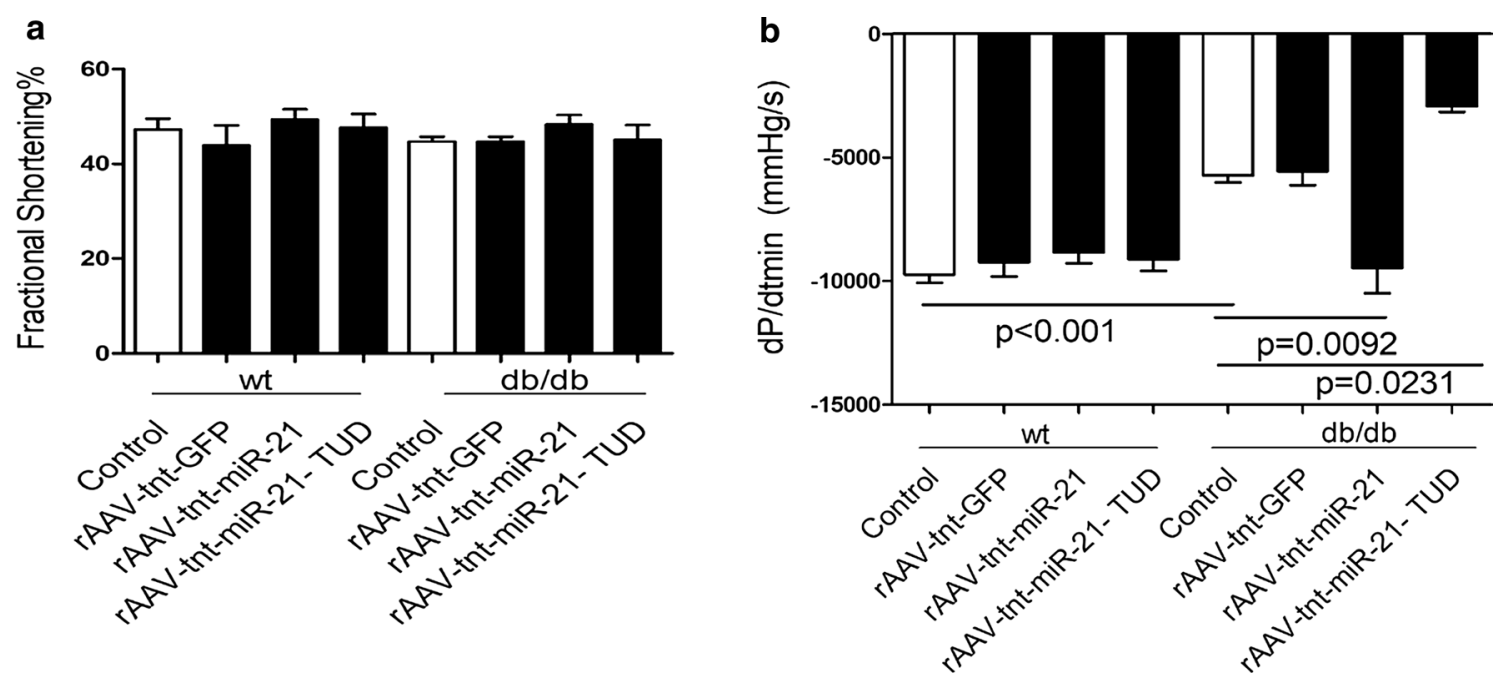

Fig. 2 Overexpression of miR-21 protects against diastolic dysfunction in $\mathrm{db} / \mathrm{db}$ mice. a Echocardiographic analysis of $\mathrm{db} / \mathrm{db}$ mice and controls. FS\% (fractional shortening) was quantitatively analyzed. $\mathbf{b}$ Hemodynamic analysis of $\mathrm{db} / \mathrm{db}$ mice and C57BL/Ks controls. $\mathrm{dp} / \mathrm{dt} \mathrm{min}_{\text {' }}$ peak instantaneous rate of LV pressure increase decline

cardiac function $[16,50]$. Consistently, miR-21 increased the expression of p-Akt(Ser473) and p-eNOS(Ser1177) in $\mathrm{db} / \mathrm{db}$ mice (Fig. 4b-d). In wild type mice, the NO level, expression of p-Akt(Ser473) and p-eNOS(Ser1177) were not changed by miR-21 (Fig. 4a-d). Meanwhile, we found that the expression of p-eNOS(Thr495) and iNOS were not affected by miR-21 in both wild type mice and $\mathrm{db} / \mathrm{db}$ mice (Additional file 1: Fig. S6).

In conclusion, our data suggested that miR-21 might protect against diastolic dysfunction by inhibiting cardiac hypertrophy via decreasing ROS level and increasing eNOS induced-NO release in $\mathrm{db} / \mathrm{db}$ mice.

\section{MiR-21 attenuates diabetic condition-induced cardiomyocyte hypertrophy in vitro}

To further determine whether the decreased miR-21 was hyperglycemia or hyperlipidemia-dependent, cultured $\mathrm{H} 9 \mathrm{c} 2$ cells were treated with high glucose, palmitate, palmitate plus glucose, respectively. Interestingly, palmitate but not glucose treatment significantly decreased miR-21 expression in $\mathrm{H} 9 \mathrm{c} 2$ cells. Palmitate plus glucose together further suppressed the palmitate-decreased miR-21 expression (Fig. 5a). Moreover, hypertrophy observed in palmitate-treated cells was significantly attenuated by miR-21 mimics treatment (Fig. $5 b$ ). Further, miR-21 decreased the expression of cardiac hypertrophy markers in palmitate-treated cells (Fig. 5c-e). All effects were enhanced by treatment of palmitate plus glucose together, comparing with palmitate alone (Fig. 5a-e). More importantly, palmitate treatment induced ROS and decreased NO level in cardiomyocytes were attenuated by miR-21 mimics transfection (Fig. 5f, g). Consistently, miR-21 increased the phosphorylation of Akt at Ser473 and eNOS at Ser1177 (Fig. 5h). Still, the expression levels of p-eNOS(Thr495) and iNOS were not changed by miR21 (Additional file 1: Fig. S7). Additionally, in physiological status, miR-21 had neither effect on cardiomyocyte area, ROS and NO levels, nor p-eNOS and iNOS expression levels (Fig. 5b-g, Additional file 1: Fig. S8). Experiments in human cardiac myocytes also showed similar results (Additional file 1: Fig. S9).

These data indicated that miR-21 attenuated cardiomyocyte hypertrophy via decreasing ROS level and increasing NO production in palmitate treated-cardiomyocyte.

\section{Gelsolin is a direct target of miR-21}

We predicted and evaluated the potential targets of miR-21 in cultured cells. As reported previously [51], we performed mRNA-microarray in diabetic cardiomyopathy ( $\mathrm{db} / \mathrm{db}$ mice) heart, and found that 69 genes were upregulated in $\mathrm{db} / \mathrm{db}$ heart (Additional file 1: Table S2). Then bioinformatic analysis was performed to identify the binding potential of miR-21 to those dysregulated genes using the BiBiServ Tool. As a result, 4 genes (Gelsolin, Adra1b, Psat1 and ZCCHC6) were predicted to be potential targets of miR-21 (Additional file 1: Fig. S10). Secondly, we performed RNA co-immunoprecipitation with Ago2 antibody, and found increased association of gelsolin (GSN) mRNA with Ago2 after miR-21 treatment in rat H9c2 cells, mouse HL-1 cells and human cardiac myocytes (Fig. 6a-c). Next, we cloned the $3^{\prime}$ UTR of human GSN (including wild-type and seed region 
a

Control

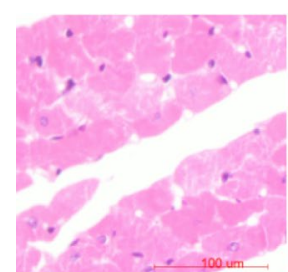

wt

$\mathrm{db} / \mathrm{db}$

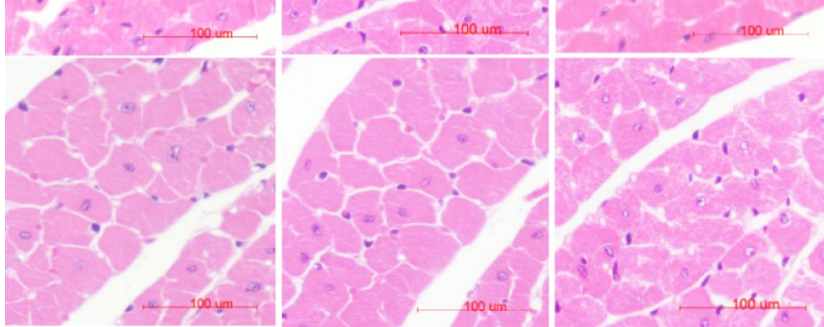

rAAV-miR-21

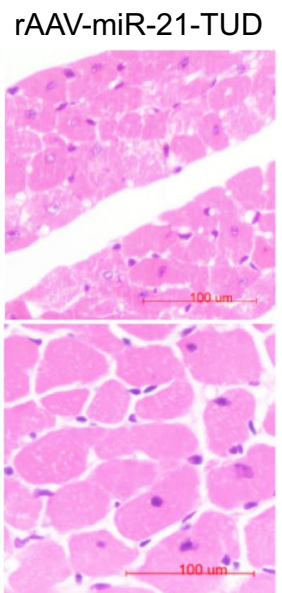

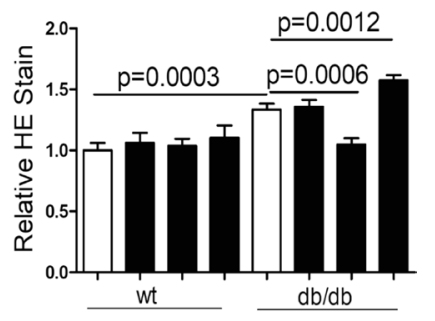

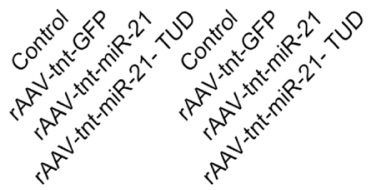

b

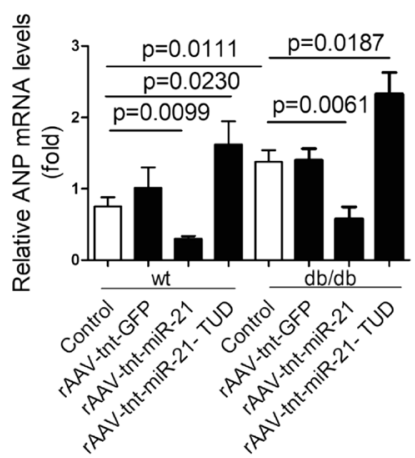

C

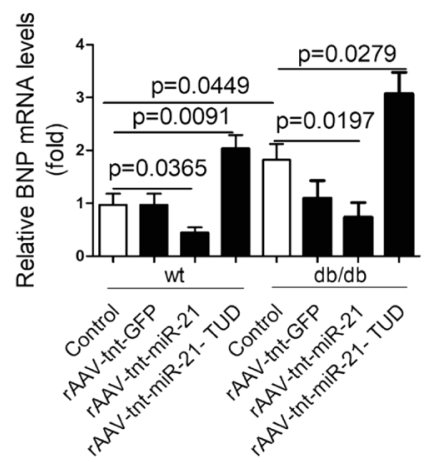

d

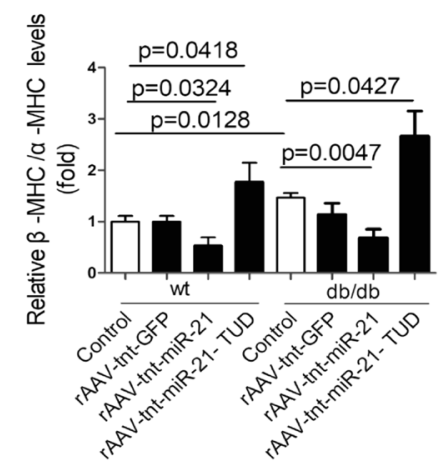

e
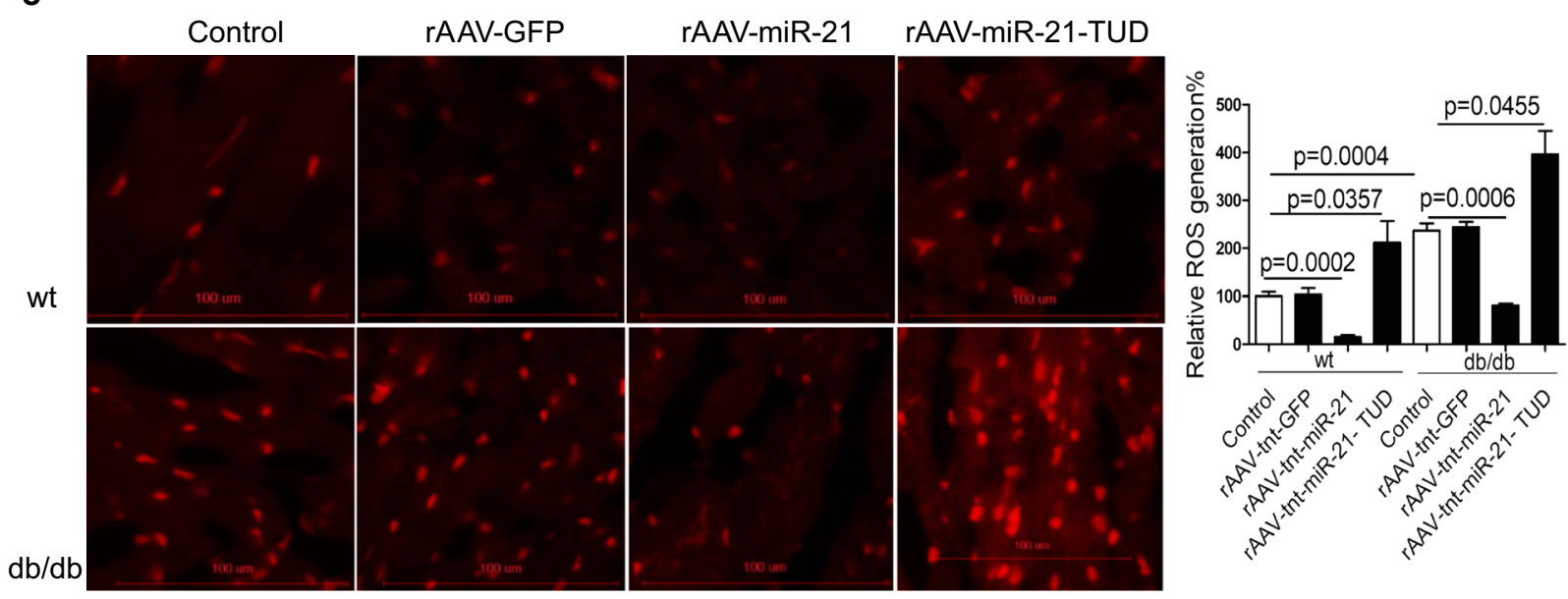

Fig. 3 MiR-21 protects against cardiac hypertrophy in diastolic dysfunction db/db mice. a Histological analysis of cardiomyocyte by H\&E staining b-d Relative expression levels of ANP, BNP, $\beta-\mathrm{MHC} / \mathrm{a}-\mathrm{MHC}$ in heart from treated mice. e Representative images of ROS detected by DHE probe in frozen heart sections of $\mathrm{db} / \mathrm{db}$ mice compared to controls

mutated sequence) to pMIR-report vector, respectively (Fig. 6d). Results showed that after co-transfecting with miR-21 mimics, the relative luciferase activity of pMIR-GSN 3' UTR in HEK293 cells was significantly suppressed compared with mimics random. However, this suppressive effect of miR-21 was abolished by mutating GSN $3^{\prime}$ UTR (Fig. 6e). Finally, Western blots showed a higher expression of GSN in cultured $\mathrm{H} 9 \mathrm{c} 2$ cells exposed 

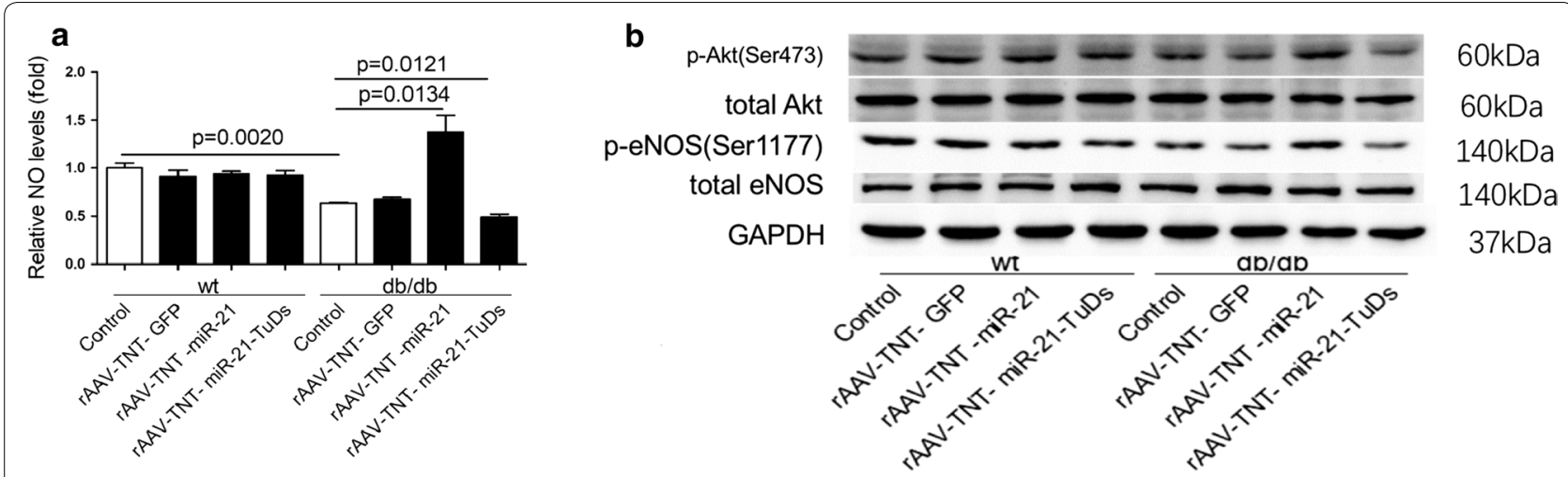

C

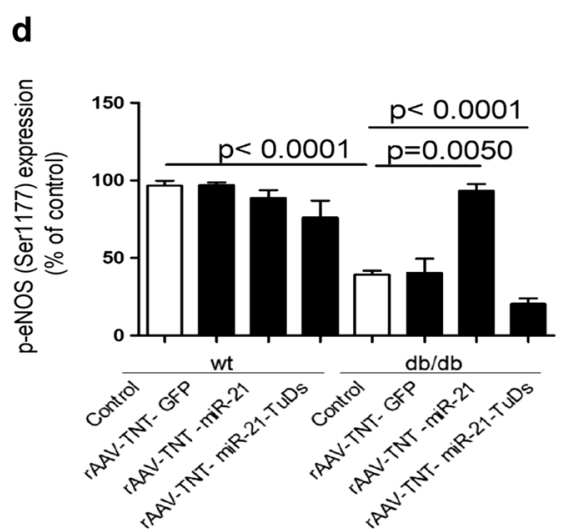

Fig. 4 MiR-21 protects against cardiac hypertrophy in diastolic dysfunction db/db mice. a Relative NO levels in heart from treated mice. b-c Protein levels of $\mathrm{p}$-Akt(Ser473) and p-eNOS(Ser1177) in heart from treated mice

to palmitate compared with control, and miR-21 transfection decreased the enhanced GSN level, while miR-21 inhibitor further increased the GSN expression (Fig. 6f). Further, western blot showed that cardiac GSN was increased in $\mathrm{db} / \mathrm{db}$ mice compared with wild type controls, and miR-21 treatment significantly reduced GSN expression in $\mathrm{db} / \mathrm{db}$ mice (Fig. 6g). These data indicated that miR-21 directly targeted GSN in vitro and in vivo.

\section{MiR-21 alleviates palmitate-induced injury via GSN}

Consistent with the effects of miR-21, down-regulation of GSN by siRNA decreased hypertrophy markers expression and ROS level, but increased NO production and expression of p-Akt(Ser473) and p-eNOS(Ser1177) in palmitate treated cells (Fig. 7a-f).

We next investigated whether miR-21 regulated cardiac hypertrophy, ROS production and NO levels via GSN pathway. Interestingly, the protective effects of miR-21 were completely blocked by GSN re-expression (Figs. 7g, $8 \mathrm{a}-\mathrm{d})$.
In conclusion, our data suggested that miR-21 attenuated palmitate-induced injury by down-regulating GSN expression.

\section{Discussion}

In the present study, we observed down-regulated cardiac miR-21 in db/db mice, which contributed to diabetic cardiomyopathy. We found that miR-21 was able to suppress GSN, an important transcriptional cofactor in signal transduction in cardiovascular diseases. Moreover, the overexpression of exogenous miR-21 efficiently protected against diastolic dysfunction and alleviated cardiac hypertrophy by decreasing ROS and improving NO release via GSN in $\mathrm{db} / \mathrm{db}$ mice, which suggested a new therapeutic strategy against diabetic cardiomyopathy (Fig. 9).

Previous findings in $\mathrm{db} / \mathrm{db}$ mice, which were characterized by progressive obese, hyperglycemia and hyperinsulinemia, revealed a strong association between altered myocardial substrate preference and cardiac dysfunction [52-54]. In the current study, db/db mice, an established animal model of diabetic cardiomyopathy, were used to 
(See figure on next page.)

Fig. 5 MiR-21 attenuates diabetic condition-induced cardiomyocyte hypertrophy in vitro. a Relative expression of miR-21 in treated H9c2 cells. b Representative images and relative cell area determined by quantitation analysis of cardiomyocyte by Phalloidin staining in treated $\mathrm{H} 9 \mathrm{c} 2$ cells. c-e Relative expression levels of ANP, BNP, and $\beta-M H C / a-M H C$ in treated H9c2 cells. $\mathbf{f}$ ROS generation in treated H9c2 cells. $\mathbf{g}$ Relative NO levels in treated H9c2 cells. h Protein levels of p-Akt(Ser473) and p-eNOS(Ser 1177) in treated H9c2 cells

study the pathological process of early diabetic cardiomyopathy [55]. Using hemodynamic examinations, we only observed decreased diastolic function in $\mathrm{db} / \mathrm{db}$ mice in the absence of measurable contractile dysfunction at the age of 20 weeks, which was consistent with previous data that cardiac diastolic dysfunction was often the earliest hallmark of diabetic cardiomyopathy $[4,5,56]$. Studies revealed that diastolic dysfunction usually occurred in isolation, or prior to systolic dysfunction [8], and diastolic dysfunction was more susceptible to preclinical changes [57].

The pathophysiology of diabetic cardiac dysfunction is complex and multifactorial. Up to now, several mechanisms of diastolic cardiac stiffness have been discovered, including increased myocardial deposition of collagen, myocardial triglyceride accumulation, cardiac hypertrophy, increased generation of ROS, and decreased NO level [3]. In our study, we observed myocardial triglyceride accumulation, cardiac hypertrophy, generation of ROS and decreased NO level in heart from $\mathrm{db} / \mathrm{db}$ mice. All these factors may initiate diastolic dysfunction, and lead to diabetic cardiomyopathy in the end complicatedly. It is widely accepted that the systolic dysfunction which might occurred in the middle or late stage of diabetic cardiomyopathy is associated with apoptosis and fibrosis. On the other hand, many studies have reported that compared with wild type mice, $\mathrm{db} / \mathrm{db}$ mice may exhibit no significant fibrosis at 12,24 , and 36 weeks old $[58,59]$. In this study, systolic dysfunction and cardiac fibrosis of $\mathrm{db} / \mathrm{db}$ mice were not observed, which matched with the early phase of diabetic cardiomyopathy, represented by diastolic dysfunction only. As diabetes progresses, there might be fibrosis in the middle or late stage of diabetic cardiomyopathy. Thus, therapies during the early stages of diabetes can potentially delay or impede the progression of various permanent sequelae.

There are multiple pathophysiologic triggers of diabetic cardiomyopathy. Hyperglycemia is one of the central drivers of the metabolic, functional and structural alterations present in the diabetic heart. Whereas FFA is the primary energy source for heart, its level is also elevated in T2DM. High circulating and cellular FFAs can directly elevate peripheral insulin resistance, stimulate apoptosis and trigger a harmful build-up of toxic intermediates, which result in lipotoxicity. These deleterious effects can contribute to impaired cardiac function and adverse remodeling in the diabetic myocardium. The diabetic heart is also characterized by inefficient utilization of glucose for energy production. Studies have reported that FFAs could inhibit glucose oxidation and enhance mitochondrial fatty acid uptake [66, 67]. As cardiac glucose oxidation decreases, cardiac energy provision is almost exclusively via $\beta$-oxidation of fatty acids. So, lipotoxicity is thought to be a central player in diabetic heart by promoting acidosis and generating free radicals, inducing ceramide, damaging the mitochondrial membrane, finally making the diabetic heart more prone to injury [68]. Many studies focused on the effects of palmitate in diabetic cardiomyopathy [23, 24]. Studies found that the confounding effects of classical risk factors coexisting in diabetes, such as hyperglycemia, insulin resistance, hyperlipidemia, metabolic disturbances and neurohormonal activation, combination with other risk factors might promote diabetic cardiomyopathy progression. It was reported that patients with type 2 diabetes, metabolic syndrome or obesity all accumulated excess intramyocardial lipid and exhibited systolic or diastolic cardiac dysfunction [3, 69, 70]. In our study, we found that glucose alone did not decrease miR-21 level, whereas palmitate decreased miR-21 level, so we focused on the effects of palmitate in the further study. Moreover, we found palmitate plus glucose together further decreased the expression of miR-21 and aggravated the damages induced by palmitate alone, which stimulate deeper investigations in the future.

MiR-21 is crucial in a number of biological functions and diseases, including development, cancer, cardiovascular diseases and inflammation [60]. In previous study, we found that miR-21 had a positive function in mitochondrial translation, which was sufficient to reduce blood pressure and alleviate cardiac hypertrophy in spontaneous hypertension rats [39]. Studies have reported and many miRNAs involved in mitochondrial dynamics and function in diabetic complications [61]. Here, we observed decreased miR-21 level in both $\mathrm{db} / \mathrm{db}$ mice and high fat diet fed mice, and miR-21 played a protective role against diabetic cardiomyopathy. In vitro, we found that miR-21 was downregulated in palmitate treated H9c2 cells, while overexpression of miR-21 attenuated the injuries induced by palmitate, suggesting a protective role in cardiomyocyte. While it has been reported that miR-21 was upregulated in fibroblasts with high 

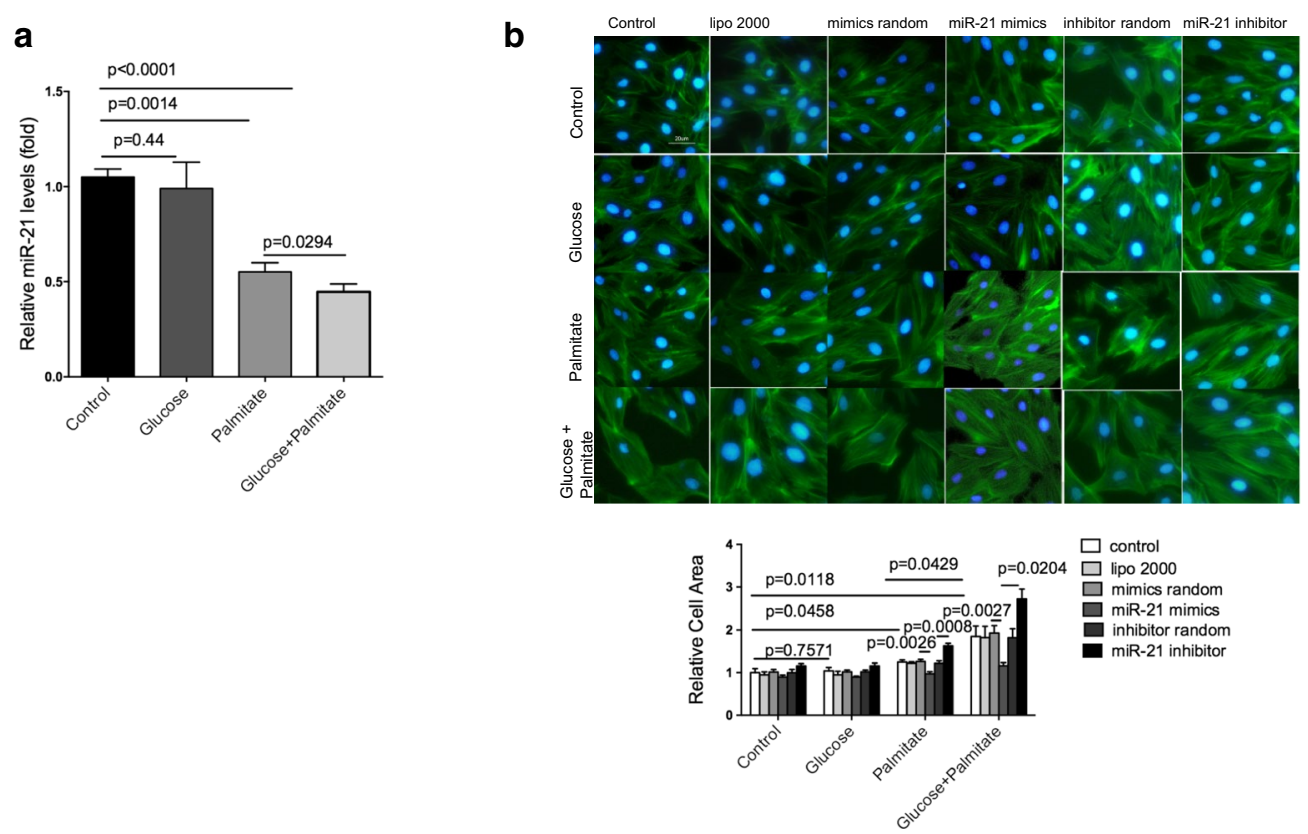

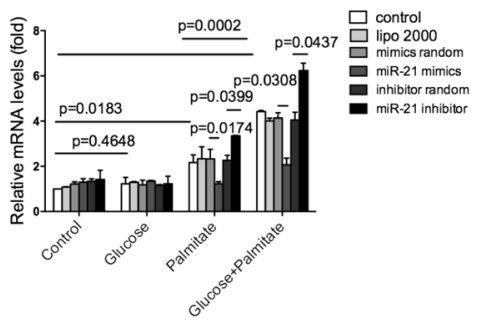

f

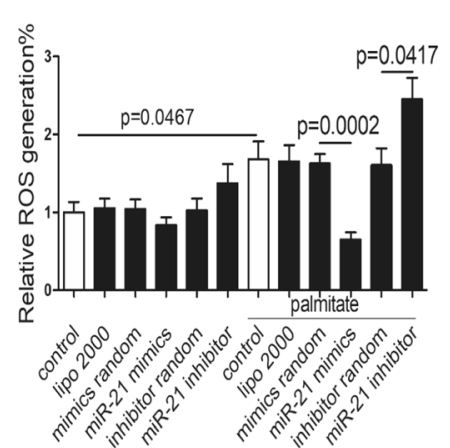

h

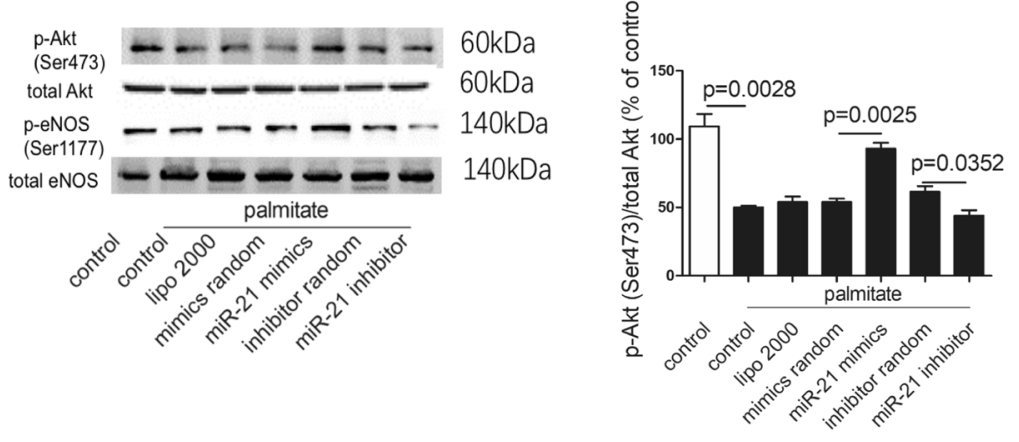

g

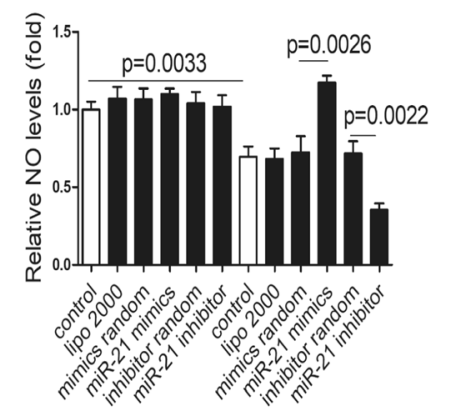

d
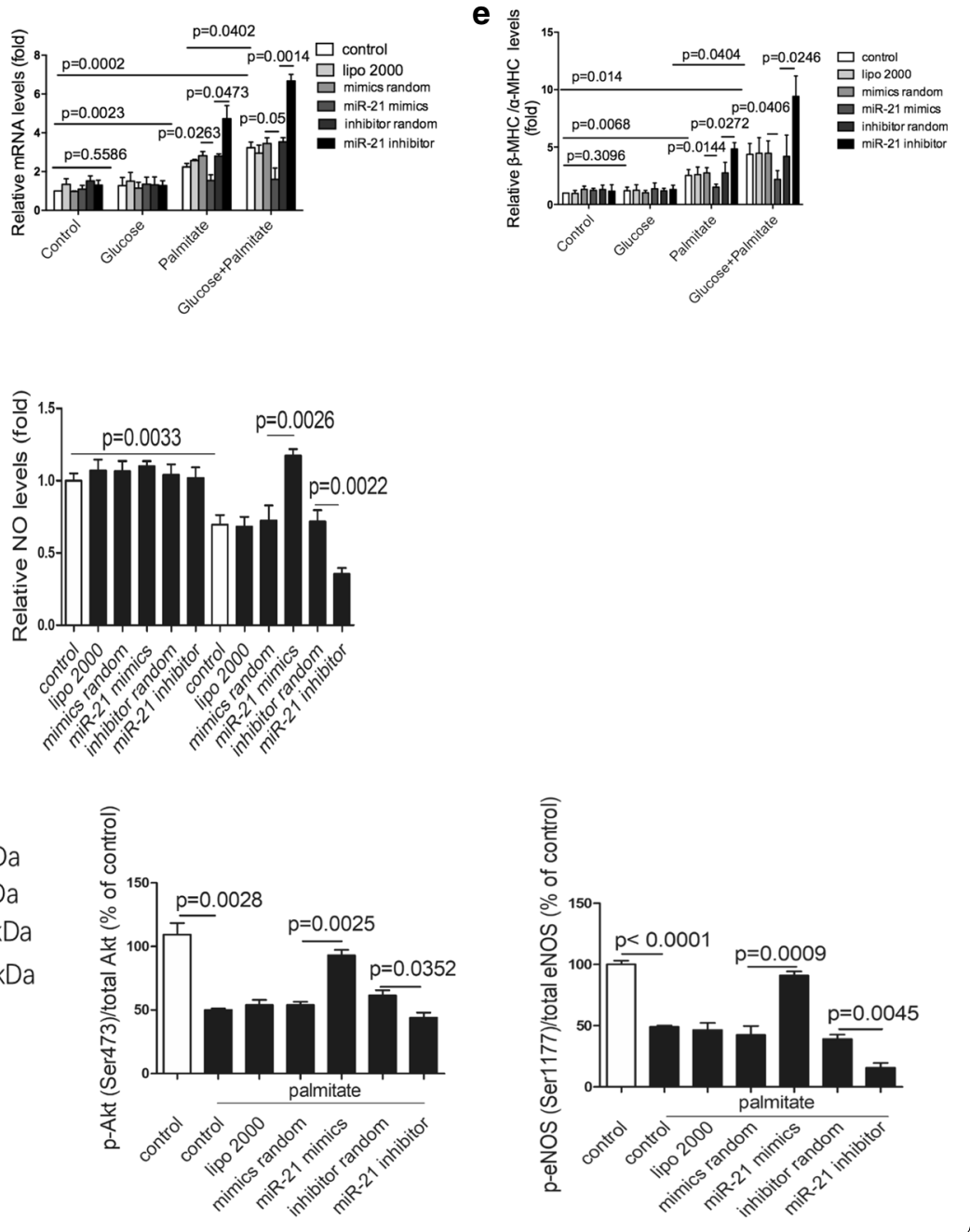


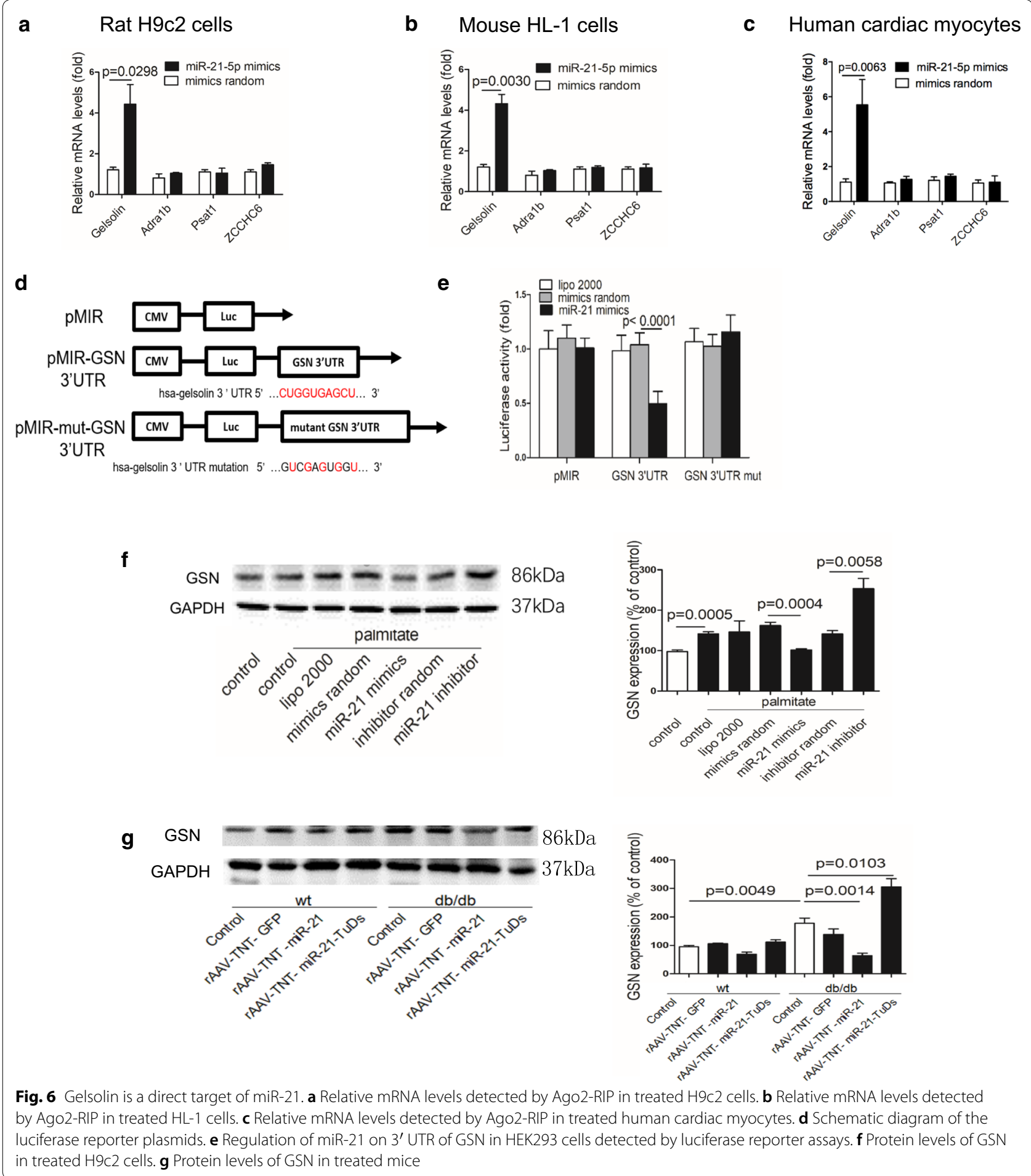

glucose treatment and exerted its harmful effects [35]. It is an interesting issue that miR-21 plays different roles in different cell types. Deepak et al. found that upon left ventricular pressure overload, cardiac function was only preserved in mice with miR-21 deficiency in nonmyocyte cardiac cells, but not in mice with global or cardiac myocyte-specific ablation [37]. Although in vitro study discovered miR-21 induced damages in high glucose treated fibroblasts [35], in vivo studies showed that miR-21 deficiency in fibroblasts or upregulation of miR-21 in cardiac 


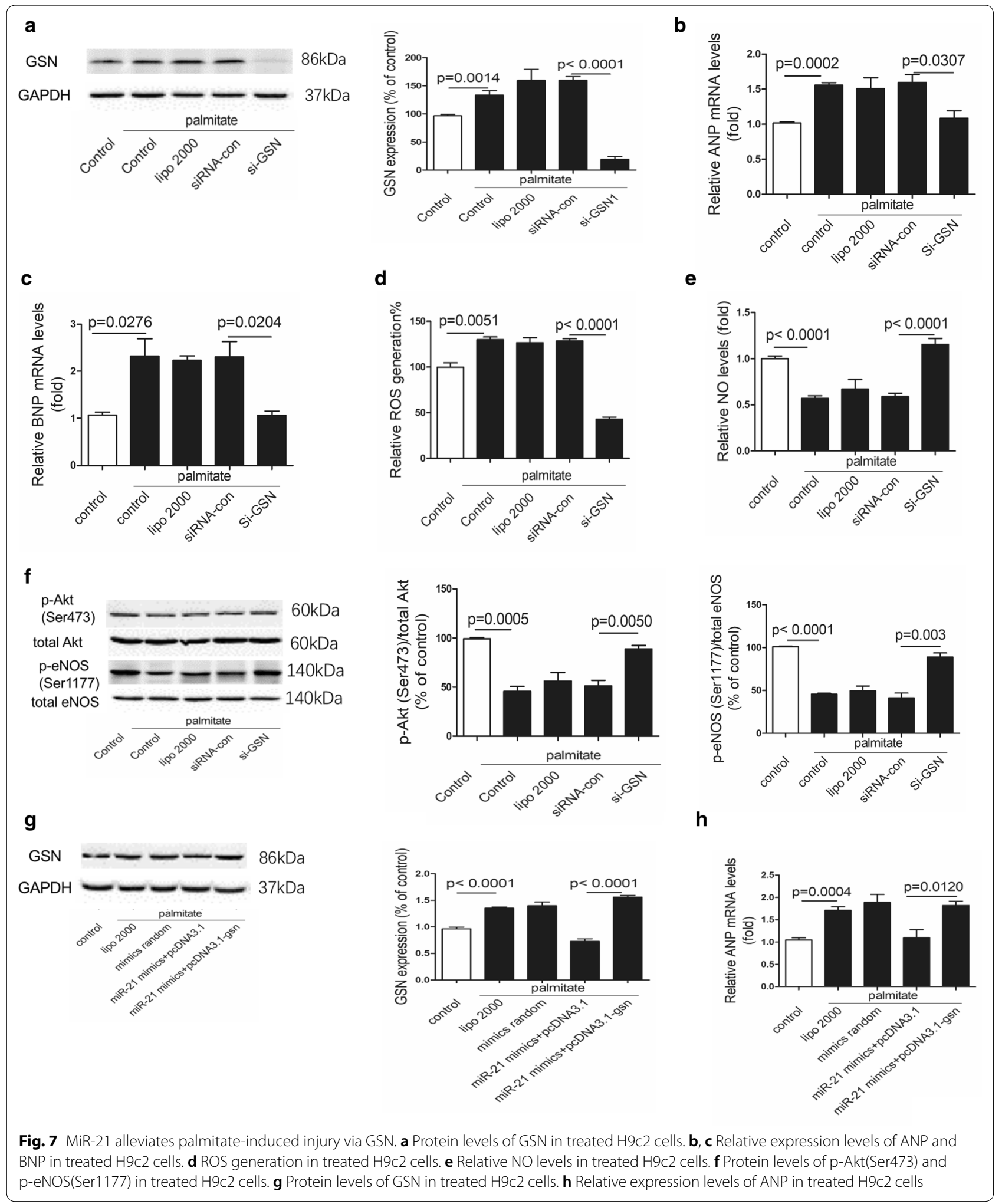



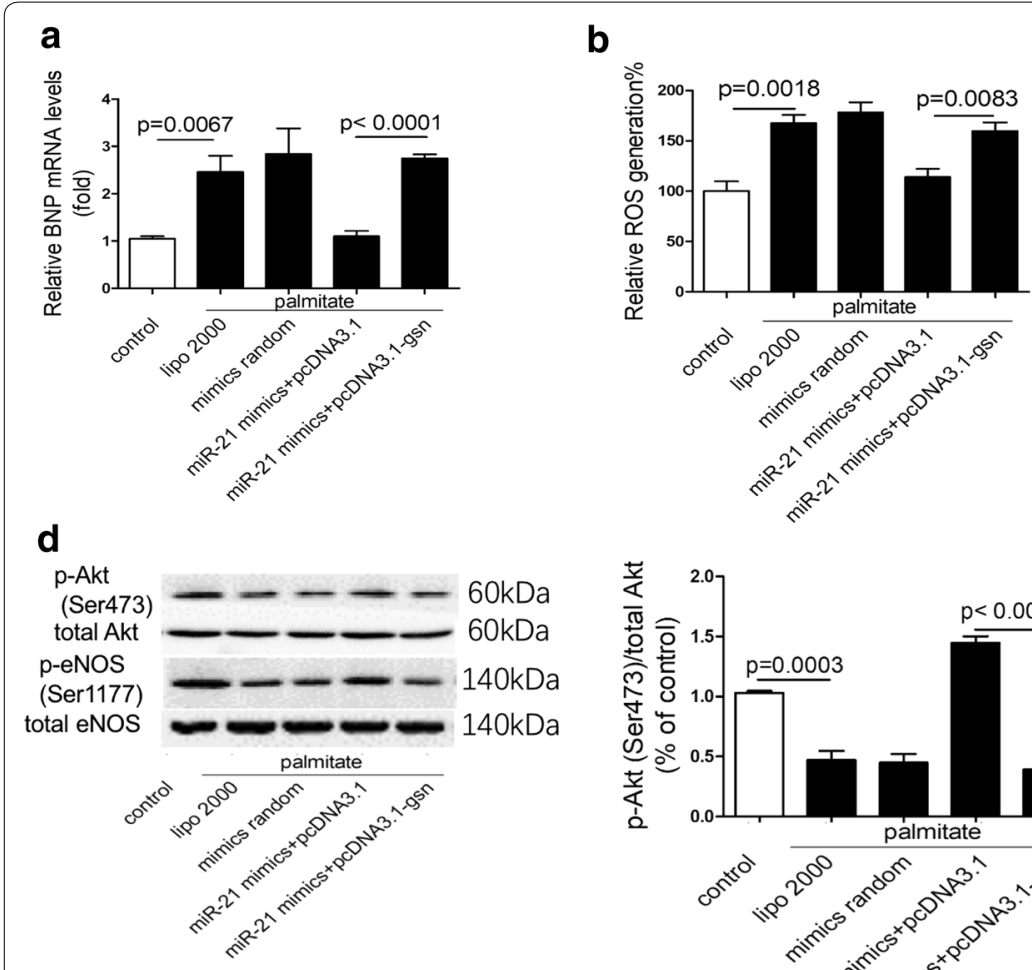

C
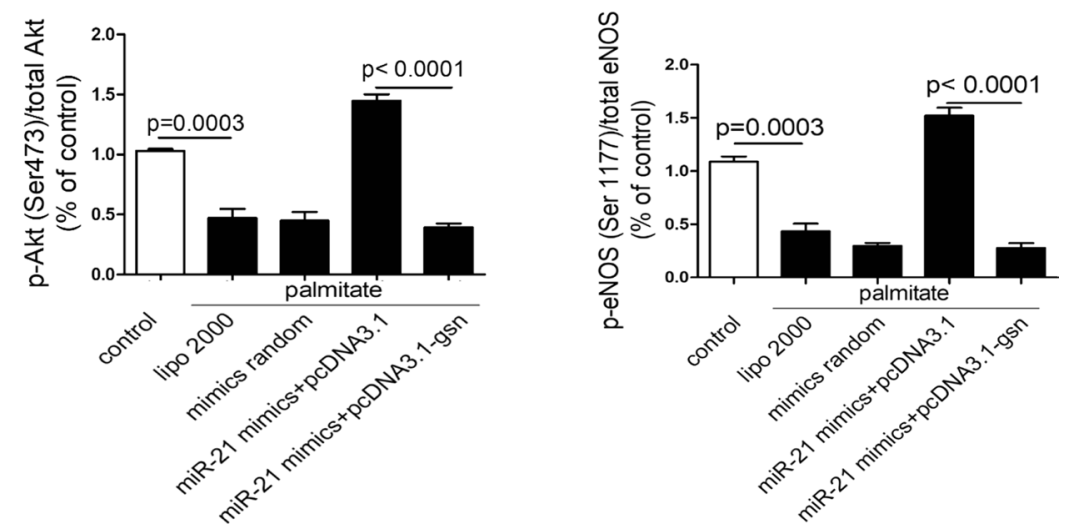

Fig. 8 MiR-21 alleviates palmitate-induced injury via GSN. a Relative expression levels of BNP in treated H9c2 cells. b ROS generation in treated $\mathrm{H} 9 \mathrm{c} 2$ cells. $\mathbf{c}$ Relative NO levels in treated H9c2 cells. $\mathbf{d}$ Protein levels of p-Akt(Ser473) and p-eNOS(Ser1177) in treated H9c2 cells

myocytes protected cardiac function in different pathological condition [34, 37]. In the current study, AAV9 system which provided high-level, stable expression in heart, combined with cardiac specific cTNT promoter was used [62]. Studies have found that this system drove high levels of expression of target gene in the myocardium, compared with other organs [63-65]. Our data demonstrated that miR-21 exerted its protective role directly in cardiac myocytes and encouraged further development of cardiac specific overexpression of miR-21 therapy toward cellular tropism.

Moreover, we verified GSN as a direct target of miR21 . The sequences of gelsolin are not highly conserved among different species; thus, we verified the binding site of miR-21 on gelsolin mRNA in human, mouse and rat cardiomyocytes by RIP. Though we identified GSN as an important target of miR-21 in diabetic cardiomyopathy, there may be still other targets of miR-21.

The expression levels of GSN in human heart tissues and mouse models were increased by different types of cardiac injuries, including pressure overload, acute myocardial infarction, dilated or ischemic cardiomyopathy, and end-stage heart failure [71-73]. Our data showed that GSN was also upregulated in $\mathrm{db} / \mathrm{db}$ mice, and siRNA against GSN alleviated cardiac damages, while overexpression of GSN showed opposite effects. This was consistent with the previous studies that overexpression of GSN in H9c2 induced cardiac hypertrophy [74]. Although some studies found that the $\mathrm{gsn}^{-/-}$animals did not show significant cardiac hypertrophy or myocyte hypertrophy, gelsolin deficiency improved cardiac systolic function [75]. Interestingly, in this study, we also found that miR-21 was sufficient to alleviate ROS via decreasing GSN which was consistent with previous studies that overexpression of GSN increased ROS level $[76,77]$. Li et al. found that the phosphorylation of Akt at Ser473 was significantly increased in gsn ${ }^{-1-}$ mice, suggesting that GSN may inhibit cell survival [72]. Interestingly, we found that in diabetic condition, si-GSN could increase NO level by increasing p-Akt(Ser473) and p-eNOS(Ser1177). Activation of the phosphoinositidedependent 3 kinase (PI-3K)/Akt axis led to eNOS phosphorylation at Ser1177 and enhanced NO production, which constituted a major protective role in ischemia/ reperfusion injury and end-stage heart failure [78-80]. Improvement of Akt-dependent eNOS activity and 


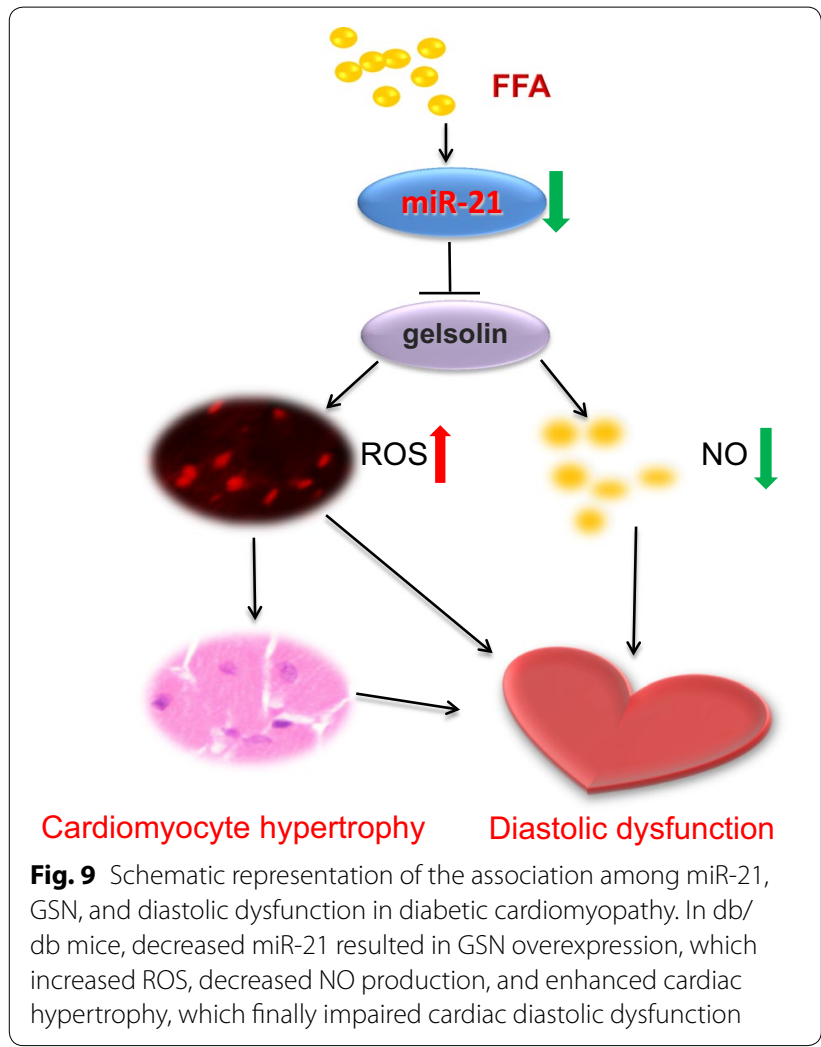

restoration of Akt-eNOS-NO signaling could attenuate myocardial dysfunction and diabetic cardiomyopathy [81]. We speculated that GSN reduced NO production via Akt-eNOS-NO signaling in diabetic cardiomyopathy induced-diastolic dysfunction.

\section{Conclusion}

Together, here we found that miR-21 improved diastolic function, which was the earliest hallmark of diabetic cardiomyopathy, and alleviated cardiac hypertrophy by reducing elevated ROS and enhancing NO production via GSN. Our data suggested that miR-21 may be a promising therapeutic target for treating diabetic cardiomyopathy.

\section{Additional file}

Additional file 1. Additional figures and tables.

\section{Abbreviations}

ROS: reactive oxygen species; NO: nitric oxide; miRNA: microRNA; eNOS: end othelial nitric oxide synthase; FA: fatty acid; FBS: fetal bovine serum; rAAV: recombinant adeno-associated virus; TUNEL: terminal dexynucleotidyl transferase (TdT)-mediated dUTP nick end labelling; TC: total cholesterol; TG: triglyceride; LDL: low-density lipoprotein; HDL: high-density lipoprotein; ANP: atrial natriuretic peptide; BNP: brain natriuretic peptide; UTR: untranslated region.

\section{Authors' contributions}

$\mathrm{BD}$ and $\mathrm{HL}$ designed the study, analysed and interpreted the data, and drafted the paper. JF, YZ, ZY, and XN contributed to data acquisition. CC and DWW designed the study and drafted the paper. All authors read and approved the final manuscript.

\section{Author details}

${ }^{1}$ Division of Cardiology, Department of Internal Medicine, Tongji Hospital, Tongji Medical College, Huazhong University of Science and Technology, 1095\# Jiefang Ave., Wuhan 430030, China. ${ }^{2}$ Hubei Key Laboratory of Genetics and Molecular Mechanisms of Cardiological Disorders, Wuhan 430030, China.

\section{Acknowledgements}

We thank our colleagues in Dr. Wang's group for technical assistance and stimulating discussions during the course of this investigation.

\section{Competing interests}

The authors declare that they have no competing interests.

\section{Availability of data and materials}

Not applicable.

\section{Consent for publication}

All the authors agree.

\section{Ethics approval and consent to participate}

Not applicable.

\section{Funding}

This work was supported by Grants from the National Natural Science Foundation of China (Nos. 81822002, 91439203, 81630010, 31771264, 31571197, and 31800973). The funders had no role in study design, data collection and analysis, manuscript preparation, or decision to publish.

\section{Publisher's Note}

Springer Nature remains neutral with regard to jurisdictional claims in published maps and institutional affiliations.

Received: 31 May 2018 Accepted: 25 August 2018

Published online: 04 September 2018

\section{References}

1. Zimmet P, Alberti KG, Shaw J. Global and societal implications of the diabetes epidemic. Nature. 2001;414:782-7.

2. Poornima IG, Parikh P, Shannon RP. Diabetic cardiomyopathy: the search for a unifying hypothesis. Circ Res. 2006;98(5):596-605.

3. Huynh K, Bernardo BC, McMullen JR, Ritchie RH. Diabetic cardiomyopathy: mechanisms and new treatment strategies targeting antioxidant signaling pathways. Pharmacol Ther. 2014;142(3):375-415.

4. Schannwell CM, Schneppenheim M, Perings S, Plehn G, Strauer BE. Left ventricular diastolic dysfunction as an early manifestation of diabetic cardiomyopathy. Cardiology. 2002;98:33-9.

5. Diamant M, Lamb HJ, Groeneveld Y, Endert EL, Smit JWA, Bax JJ, Romijn JA, de Roos A, Radder JK. Diastolic dysfunction is associated with altered myocardial metabolism in asymptomatic normotensive patients with well-controlled type 2 diabetes mellitus. J Am Coll Cardiol. 2003;42(2):328-35.

6. Palmieri V, Capaldo B, Russo C, laccarino M, Pezzullo S, Quintavalle G, Di Minno G, Riccardi G, Celentano A. Uncomplicated type 1 diabetes and preclinical left ventricular myocardial dysfunction: insights from echocardiography and exercise cardiac performance evaluation. Diabetes Res Clin Pract. 2008;79(2):262-8

7. Mori J, Patel VB, Abo Alrob O, Basu R, Altamimi T, Desaulniers J, Wagg CS, Kassiri Z, Lopaschuk GD, Oudit GY. Angiotensin 1-7 ameliorates diabetic 
cardiomyopathy and diastolic dysfunction in $\mathrm{db} / \mathrm{db}$ mice by reducing lipotoxicity and inflammation. Circ Heart Fail. 2014;7(2):327-39.

8. van Heerebeek L, Hamdani N, Handoko ML, Falcao-Pires I, Musters RJ, Kupreishvili K, Ijsselmuiden AJ, Schalkwijk CG, Bronzwaer JG, Diamant M, et al. Diastolic stiffness of the failing diabetic heart: importance of fibrosis, advanced glycation end products, and myocyte resting tension. Circulation. 2008;117(1):43-51.

9. McMurray JJ, Stewart S. Epidemiology, aetiology, and prognosis of heart failure. Heart. 2000:83:596-602.

10. Kitzman DW, Gardin JM, Gottdiener JS, Arnold A, Boineau R. Importance of heart failure with preserved systolic function in patients $>65$ years of age. Am J Cardiol. 2001;87:413-9.

11. Katsufumi M, Li Y, Takahisa N, Hideyasu K, Yang Y, Naohisa H, Koji O, Hirohide M. Alteration in left ventricular diastolic filling and accumulation of myocardial collagen at insulin-resistant prediabetic stage of a type II diabetic rat model. Circulation. 2000;101:899-907.

12. Huynh K, Kiriazis H, Du XJ, Love JE, Gray SP, Jandeleit-Dahm KA, McMullen $\mathrm{JR}$, Ritchie RH. Targeting the upregulation of reactive oxygen species subsequent to hyperglycemia prevents type 1 diabetic cardiomyopathy in mice. Free Radic Biol Med. 2013:60:307-17.

13. Huynh K, Kiriazis H, Du XJ, Love JE, Jandeleit-Dahm KA, Forbes JM, McMullen JR, Ritchie RH. Coenzyme Q10 attenuates diastolic dysfunction, cardiomyocyte hypertrophy and cardiac fibrosis in the $\mathrm{db} / \mathrm{db}$ mouse model of type 2 diabetes. Diabetologia. 2012;55(5):1544-53.

14. Jia G, Habibi J, DeMarco VG, Martinez-Lemus LA, Ma L, Whaley-Connell AT, Aroor AR, Domeier TL, Zhu Y, Meininger GA, et al. Endothelial mineralocorticoid receptor deletion prevents diet-induced cardiac diastolic dysfunction in females. Hypertension. 2015;66(6):1159-67.

15. Atkinson LL, Kozak R, Kelly SE, Besikci AO, Russell JC, Lopaschuk GD. Potential mechanisms and consequences of cardiac triacylglycerol accumulation in insulin-resistant rats. Am J Physiol Endocrinol Metab. 2003;284:E923-30.

16. Lei S, Li H, Xu J, Liu Y, Gao X, Wang J, Ng KF, Lau WB, Ma XL, Rodrigues B, et al. Hyperglycemia-induced protein kinase $C$ beta2 activation induces diastolic cardiac dysfunction in diabetic rats by impairing caveolin-3 expression and Akt/eNOS signaling. Diabetes. 2013;62(7):2318-28.

17. van Rooij E. The art of microRNA research. Circ Res. 2011;108(2):219-34.

18. Shah MS, Brownlee M. Molecular and cellular mechanisms of cardiovascular disorders in diabetes. Circ Res. 2016;118(11):1808-29.

19. Russell J, Du Toit EF, Peart JN, Patel HH, Headrick JP. Myocyte membrane and microdomain modifications in diabetes: determinants of ischemic tolerance and cardioprotection. Cardiovasc Diabetol. 2017:16(1):155

20. La Sala L, Cattaneo M, De Nigris V, Pujadas G, Testa R, Bonfigli AR, Genovese $\mathrm{S}$, Ceriello A. Oscillating glucose induces microRNA-185 and impairs an efficient antioxidant response in human endothelial cells. Cardiovasc Diabetol. 2016;15(1):71.

21. Zhu H, Yang Y, Wang Y, Li J, Schiller PW, Peng T. MicroRNA-195 promotes palmitate-induced apoptosis in cardiomyocytes by down-regulating Sirt1. Cardiovasc Res. 2011;92(1):75-84

22. Li X, Du N, Zhang Q, Li J, Chen X, Liu X, Hu Y, Qin W, Shen N, Xu C, et al. MicroRNA-30d regulates cardiomyocyte pyroptosis by directly targeting foxo3a in diabetic cardiomyopathy. Cell Death Dis. 2014;5:e1479.

23. Kuwabara Y, Horie T, Baba O, Watanabe S, Nishiga M, Usami S, Izuhara M, Nakao T, Nishino T, Otsu K, et al. MicroRNA-451 exacerbates lipotoxicity in cardiac myocytes and high-fat diet-induced cardiac hypertrophy in mice through suppression of the LKB1/AMPK pathway. Circ Res. 2015:116(2):279-88

24. Chen C, Yang S, Li H, Yin Z, Fan J, Zhao Y, Gong W, Yan M, Wang DW. MiR$30 \mathrm{c}$ is involved in diabetic cardiomyopathy through regulation of cardiac autophagy via BECN1. Mol Ther Nucleic Acids. 2017;7:127-39.

25. Villard A, Marchand L. Diagnostic value of cell-free circulating micrornas for obesity and type 2 diabetes: a meta-analysis. J Mol Biomark Diagn. 2015;06(06):251.

26. Giannella A, Radu CM, Franco L, Campello E, Simioni P, Avogaro A, de Kreutzenberg SV, Ceolotto G. Circulating levels and characterization of microparticles in patients with different degrees of glucose tolerance. Cardiovasc Diabetol. 2017;16:1

27. Zampetaki A, Kiechl S, Drozdov I, Willeit P, Mayr U, Prokopi M, Mayr A, Weger S, Oberhollenzer F, Bonora E, et al. Plasma microRNA profiling reveals loss of endothelial miR-126 and other microRNAs in type 2 diabetes. Circ Res. 2010;107(6):810-7.
28. Jansen F, Wang H, Przybilla D, Franklin BS, Dolf A, Pfeifer P, Schmitz T, Flender A, Endl E, Nickenig G, et al. Vascular endothelial microparticlesincorporated microRNAs are altered in patients with diabetes mellitus. Cardiovasc Diabetol. 2016;15:49.

29. Pearson JK. Exercise mediated protection of diabetic heart through modulation of microRNA mediated molecular pathways. Cardiovasc Diabetol. 2017;16:10.

30. Kandula V, Kosuru R, Li H, Yan D, Zhu Q, Lian Q, Ge RS, Xia Z, Irwin MG. Forkhead box transcription factor 1: role in the pathogenesis of diabetic cardiomyopathy. Cardiovasc Diabetol. 2016;15:44.

31. Seeger T, Fischer A, Muhly-Reinholz M, Zeiher AM, Dimmeler S. Long-term inhibition of miR-21 leads to reduction of obesity in $\mathrm{db} / \mathrm{db}$ mice. Obesity (Silver Spring). 2014;22(11):2352-60.

32. Lopes MB, Freitas RC, Hirata MH, Hirata RD, Rezende AA, Silbiger VN, Bortolin RH, Luchessi AD. mRNA-miRNAintegrativeanalysisofdiabetesinducedcardiomyopathyinrats. Front Biosci. 2017;9:194-229.

33. Thum T, Gross C, Fiedler J, Fischer T, Kissler S, Bussen M, Galuppo P, Just $\mathrm{S}$, Rottbauer W, Frantz S, et al. MicroRNA-21 contributes to myocardial disease by stimulating MAP kinase signalling in fibroblasts. Nature. 2008:456(7224):980-4.

34. Cheng Y, Liu X, Zhang S, Lin Y, Yang J, Zhang C. MicroRNA-21 protects against the $\mathrm{H}(2) \mathrm{O}(2)$-induced injury on cardiac myocytes via its target gene PDCD4. J Mol Cell Cardiol. 2009;47(1):5-14.

35. Liu S, Li W, Xu M, Huang H, Wang J, Chen X. Micro-RNA 21 Targets dual specific phosphatase 8 to promote collagen synthesis in high glucosetreated primary cardiac fibroblasts. Can J Cardiol. 2014;30(12):1689-99.

36. Ling HY, Hu B, Hu XB, Zhong J, Feng SD, Qin L, Liu G, Wen GB, Liao DF. MiRNA-21 reverses high glucose and high insulin induced insulin resistance in 3T3-L1 adipocytes through targeting phosphatase and tensin homologue. Exp Clin Endocrinol Diabetes. 2012;120(9):553-9.

37. Ramanujam D, Sassi Y, Laggerbauer B, Engelhardt S. Viral vector-based targeting of mir-21 in cardiac nonmyocyte cells reduces pathologic remodeling of the heart. Mol Ther. 2016;24(11):1939-48.

38. Martelli F, McGahon MK, Yarham JM, Daly A, Guduric-Fuchs J, Ferguson LJ, Simpson DA, Collins A. Distinctive profile of IsomiR expression and novel MicroRNAs in rat heart left ventricle. PLoS ONE. 2013;8(6):e65809.

39. Li H, Zhang X, Wang F, Zhou L, Yin Z, Fan J, Nie X, Wang P, Fu XD, Chen $C$, et al. MicroRNA-21 lowers blood pressure in spontaneous hypertensive rats by upregulating mitochondrial translation. Circulation. 2016;134(10):734-51.

40. Kuznetsov AV, Javadov S, Sickinger S, Frotschnig S, Grimm M. H9c2 and HL-1 cells demonstrate distinct features of energy metabolism, mitochondrial function and sensitivity to hypoxia-reoxygenation. Biochimica et Biophysica Acta (BBA). 2015;1853(2):276-84.

41. Graham EL, Balla C, Franchino H, Melman Y, del Monte F, Das S. Isolation, culture, and functional characterization of adult mouse cardiomyoctyes. J Vis Exp. 2013;79:e50289.

42. Liu X, Xiao J, Zhu H, Wei X, Platt C, Damilano F, Xiao C, Bezzerides V, Bostrom P, Che L, et al. miR-222 is necessary for exercise-induced cardiac growth and protects against pathological cardiac remodeling. Cell Metab. 2015;21(4):584-95.

43. Song YM, Song SO, Jung YK, Kang ES, Cha BS, Lee HC, Lee BW. Dimethyl sulfoxide reduces hepatocellular lipid accumulation through autophagy induction. Autophagy. 2012;8(7):1085-97.

44. Liu X, Cheng Y, Zhang S, Lin Y, Yang J, Zhang C. A necessary role of miR-221 and miR-222 in vascular smooth muscle cell proliferation and neointimal hyperplasia. Circ Res. 2009;104(4):476-87.

45. Yin Z, Zhao Y, Li H, Yan M, Zhou L, Chen C, Wang DW. MiR-320a mediates doxorubicin-induced cardiotoxicity by targeting VEGF signal pathway. Ageing. 2016;8(1):192.

46. Jiang JG, Ning YG, Chen C, Ma D, Liu ZJ, Yang S, Zhou J, Xiao X, Zhang XA, Edin ML, et al. Cytochrome p450 epoxygenase promotes human cancer metastasis. Cancer Res. 2007;67(14):6665-74.

47. Hu Z, Crump SM, Zhang P, Abbott GW. Kcne2 deletion attenuates acute post-ischaemia/reperfusion myocardial infarction. Cardiovasc Res. 2016:110:227-37.

48. Dludla PV, Essop MF, Gabuza KB, Muller CJF, Louw J, Johnson R. Agedependent development of left ventricular wall thickness in type 2 diabetic $(\mathrm{db} / \mathrm{db})$ mice is associated with elevated low-density lipoprotein and triglyceride serum levels. Heart Vessels. 2017;32(8):1025-31. 
49. Ritchie RH, Leo $\mathrm{CH}$, Qin C, Stephenson EJ, Bowden MA, Buxton KD, Lessard SJ, Rivas DA, Koch LG, Britton SL, et al. Low intrinsic exercise capacity in rats predisposes to age-dependent cardiac remodeling independent of macrovascular function. Am J Physiol Heart Circ Physiol. 2013;304(5):H729-39.

50. Murfitt L, Whiteley G, Iqbal MM, Kitmitto A. Targeting caveolin-3 for the treatment of diabetic cardiomyopathy. Pharmacol Ther. 2015;151:50-71.

51. Peng T, Yang S, Chen C, Wang H, Rao X, Wang F, Duan Q, Chen F, Long G, Gong W, et al. Protective effects of Acyl-coA thioesterase 1 on diabetic heart via PPARa/PGC1 a signaling. PLOS ONE. 2012;7(11):e50376.

52. Hall ME, Harmancey R, Stec DE. Lean heart: role of leptin in cardiac hypertrophy and metabolism. World J Cardiol. 2015;7(9):511-24.

53. Abel ED, Litwin SE, Sweeney G. Cardiac remodeling in obesity. Physiol Rev. 2008;88(2):389-419.

54. Belke DD, Larsen TS, Gibbs EM, David LS. Altered metabolism causes cardiac dysfunction in perfused hearts from diabetic $(\mathrm{db} / \mathrm{db})$ mice. Am J Physiol Endocrinol Metab. 2000;279:1104-13.

55. Hsueh W, Abel ED, Breslow JL, Maeda N, Davis RC, Fisher EA, Dansky H, McClain DA, Mclndoe R, Wassef MK, et al. Recipes for creating animal models of diabetic cardiovascular disease. Circ Res. 2007;100(10):1415-27.

56. Huynh K, McMullen JR, Julius TL, Tan JW, Love JE, Cemerlang N, Kiriazis H, Du XJ, Ritchie RH. Cardiac-specific IGF-1 receptor transgenic expression protects against cardiac fibrosis and diastolic dysfunction in a mouse model of diabetic cardiomyopathy. Diabetes. 2010;59(6):1512-20.

57. Fang ZY, Prins JB, Marwick TH. Diabetic cardiomyopathy: evidence, mechanisms, and therapeutic implications. Endocr Rev. 2004;25(4):543-67.

58. Van den Bergh A, Vanderper A, Vangheluwe P, Desjardins F, Nevelsteen I, Verreth W, Wuytack F, Holvoet P, Flameng W, Balligand J-L, et al. Dyslipidaemia in type II diabetic mice does not aggravate contractile impairment but increases ventricular stiffness. Cardiovasc Res. 2008;77(2):371-9.

59. Van den Bergh A, Vangheluwe $P$, Vanderper A, Carmeliet P, Wuytack F, Janssens S, Flameng W, Holvoet P, Herijgers P. Food-restriction in obese dyslipidaemic diabetic mice partially restores basal contractility but not contractile reserve. Eur J Heart Fail. 2009;11(12):1118-25.

60. Xu HF, Ding YJ, Zhang ZX, Wang ZF, Luo CL, Li BX, Shen YW, Tao LY, Zhao ZQ. MicroRNA21 regulation of the progression of viral myocarditis to dilated cardiomyopathy. Mol Med Rep. 2014;10(1):161-8.

61. Cheng Z, Almeida F. Mitochondrial alteration in type 2 diabetes and obesity: an epigenetic link. Cell Cycle. 2014;13(6):890-7.

62. Bish LT, Morine K, Sleeper MM, Sanmiguel J, Wu D, Gao G, Wilson JM Sweeney HL. Adeno-associated virus (AAV) serotype 9 provides global cardiac gene transfer superior to AAV1, AAV6, AAV7, and AAV8 in the mouse and rat. Hum Gene Ther. 2008;19(12):1359-68.

63. Chamberlain K, Riyad JM, Garnett T, Kohlbrenner E, Mookerjee A, Elmastour F, Benard L, Chen J, VandenDriessche T, Chuah MK et al. A calsequestrin cis-regulatory motif coupled to a cardiac troponin t promoter improves cardiac adeno-associated virus serotype 9 transduction specificity. Hum Gene Ther. 2018;29(8):927-37.

64. Prasad KMR, Xu Y, Yang Z, Acton ST, French BA. Robust cardiomyocytespecific gene expression following systemic injection of AAV: in vivo gene delivery follows a Poisson distribution. Gene Ther. 2010;18(1):43-52.

65. Werfel S, Jungmann A, Lehmann L, Ksienzyk J, Bekeredjian R, Kaya Z, Leuchs B, Nordheim A, Backs J, Engelhardt S, et al. Rapid and highly efficient inducible cardiac gene knockout in adult mice using AAV-mediated expression of Cre recombinase. Cardiovasc Res. 2014;104(1):15-23.
66. Kaczmarczyk SJ, Andrikopoulos S, Favaloro J. Threshold effects of glucose transporter-4 (GLUT4) deficiency on cardiac glucose uptake and development of hypertrophy. J Mol Endocrinol. 2003;31:449-59.

67. Hopkins TA, Sugden MC, Holness MJ, Kozak R, Dyck JRB, Lopaschuk GD. Control of cardiac pyruvate dehydrogenase activity in peroxisome proliferator-activated receptor-a transgenic mice. Am J Physiol Heart Circ Physiol. 2003;285(1):H270-6.

68. Ghosh S, Rodrigues B. Cardiac cell death in early diabetes and its modulation by dietary fatty acids. Biochim Biophys Acta. 2006;1761(10):1148-62.

69. Goldberg IJ, Trent CM, Schulze PC. Lipid metabolism and toxicity in the heart. Cell Metab. 2012;15(6):805-12.

70. Wende AR, Abel ED. Lipotoxicity in the heart. Biochim Biophys Acta. 2010;1801(3):311-9.

71. Yang J, Moravec CS, Sussman MA, DiPaola NR. Decreased SLIM1 expression and increased gelsolin expression in failing human hearts measured by high-density oligonucleotide arrays. Circulation. 2000;102:3046-52.

72. Li GH, Shi Y, Chen Y, Sun M, Sader S, Maekawa Y, Arab S, Dawood F, Chen M, De Couto G, et al. Gelsolin regulates cardiac remodeling after myocardial infarction through DNase I-mediated apoptosis. Circ Res. 2009;104(7):896-904.

73. Mani SK, Shiraishi H, Balasubramanian S, Yamane K, Chellaiah M, Cooper G, Banik N, Zile MR, Kuppuswamy D. In vivo administration of calpeptin attenuates calpain activation and cardiomyocyte loss in pressure-overloaded feline myocardium. Am J Physiol Heart Circ Physiol. 2008:295(1):H314-26.

74. Hu WS, Ho TJ, Pai P, Chung LC, Kuo CH, Chang SH, Tsai FJ, Tsai CH, Jie YC, Liou YM, et al. Gelsolin (GSN) induces cardiomyocyte hypertrophy and BNP expression via p38 signaling and GATA-4 transcriptional factor activation. Mol Cell Biochem. 2014;390(1-2):263-70.

75. Weisser-thomas JKH, Nickenig G, Grohe C, Djoufack P. Influence of gelsolin deficiency on excitation contraction coupling in adult murine cardiomyocytes. J Physiol Pharmacol. 2015;66(3):373-83.

76. Li Q, Ye Z, Wen J, Ma L, He Y, Lian G, Wang Z, Wei L, Wu D, Jiang B. Gelsolin, but not its cleavage, is required for TNF-induced ROS generation and apoptosis in MCF-7 cells. Biochem Biophys Res Commun. 2009:385(2):284-9.

77. Tochhawng L, Deng S, Pugalenthi G, Kumar AP. Gelsolin-CuZnSOD interaction alters intracellular reactive oxygen species levels to promote cancer cell invasion. Oncotarget. 2015;7(33):52832-48.

78. Fulton D, Gratton JP, McCabe TJ, Fontana J, Fujio Y, Walsh K, Franke TF, Papapetropoulos A, Sessa WC. Regulation of endotheliumderived nitric oxide production by the protein kinase Akt. Nature. 1999;399(6736):597-601.

79. Heusch G. Molecular basis of cardioprotection: signal transduction in ischemic pre-, post-, and remote conditioning. Circ Res. 2015;116(4):674-99.

80. Fukushima H, Kobayashi N, Takeshima H, Koguchi W, Ishimitsu T. Effects of olmesartan on Apelin/APJ and Akt/endothelial nitric oxide synthase pathway in Dahl rats with end-stage heart failure. J Cardiovasc Pharmacol. 2010;55(1):83-8.

81. Ren J, Duan J, Thomas DP, Yang X, Sreejayan N, Sowers JR, Leri A, Kajstura J, Gao F, Anversa P. IGF-I alleviates diabetes-induced RhoA activation, eNOS uncoupling, and myocardial dysfunction. Am J Physiol Regul Integr Comp Physiol. 2008;294(3):R793-802.

Ready to submit your research? Choose BMC and benefit from:

- fast, convenient online submission

- thorough peer review by experienced researchers in your field

- rapid publication on acceptance

- support for research data, including large and complex data types

- gold Open Access which fosters wider collaboration and increased citations

- maximum visibility for your research: over 100M website views per year

At $\mathrm{BMC}$, research is always in progress.

Learn more biomedcentral.com/submissions 